\title{
纤维素及其衍生物负载铜催化有机反应的研究进展
}

\author{
陈 金金 $a, b$ 陈春霞 $*, a, b$ 彭进松*,a \\ ( $a$ 东北林业大学 化学化工与资源利用学院 哈尔滨 150040) \\ ( $b$ 东北林业大学 材料科学与工程学院 哈尔滨 150040)
}

\begin{abstract}
摘要 纤维素作为自然界中含量最丰富的天然聚合物, 存在于高等植物、棉花、藻类和细菌等各种物质中, 并且被科 研工作者作为金属纳米粒子的负载材料用于有机合成和催化的研究中. 近代以来，过渡金属催化领域发展迅猛，但由 于存在着成本高、分离难以及不可回收再利用等缺点, 所以越来越多的科研工作者利用纤维素及其衍生物负载过渡金 属, 实现非均相催化. 从经济高效的角度来看, 纤维素及其衍生物负载廉价金属铜粒子, 不仅可以高效地参与各种类 型的有机转化, 还能多次循环、再生利用, 解决了均相催化剂的诸多弊端, 实现绿色化学. 以不同类型纤维素铜催化剂 的制备途径为线索, 对其催化的有机反应进行了综述, 主要涉及 $\mathrm{C}-\mathrm{X}$ 键的构建、环加成、氧化、还原、光催化降解和 电催化等反应类型, 为今后纤维素及其衍生物催化剂的广泛应用起到推动作用.
\end{abstract}

关键词 纤维素负载铜催化剂; 功能化纤维素; 合成制备; 有机反应; 非均相催化

\section{Research Progress of Cellulose and Its Derivatives Supported Copper Catalyst Catalyzed Organic Reactions}

\author{
Chen, Xin ${ }^{a, b}$ Chen, Chunxia ${ }^{*, a, b} \quad$ Peng, Jinsong ${ }^{*, a}$ \\ ( ${ }^{a}$ College of Chemistry, Chemical Engineering and Resource Utilization, Northeast Forestry University, Harbin 150040) \\ ( ${ }^{b}$ Material Science and Engineering College, Northeast Forestry University, Harbin 150040)
}

\begin{abstract}
Cellulose, the most abundant natural polymer in nature, is found in vascular plant, cotton, algae and bacteria, and it can be widely employed in organic synthesis and catalytic chemistry as a loading material for metal nanoparticles. In modern times, the field of transition metal catalysis has been developed rapidly, but it has the disadvantages of high cost, difficulty of separation and non-recyclable reuse, thus more and more researchers use cellulose and its derivatives to carry out heterogeneous catalysis. From an economic and efficient point of view, cheap cellulose and its derivatives-loaded copper particles can not only participate in various types of organic conversion efficiently, but also can be recycled and reused many times, thus solving many disadvantages of homogeneous catalysts and achieving green process. The organic reactions catalyzed by different types of cellulose-supported copper catalysts are reviewed, including the construction of $\mathrm{C}-\mathrm{X}$ bond, cycloaddition, oxidation, reduction, photocatalytic degradation and electrocatalysis. It will promote the application of cellulose and its derivatives-supported catalysts in the future.
\end{abstract}

Keywords cellulose-supported copper catalyst; functional cellulose; synthesis; organic reaction; heterogeneous catalysis

随着社会环保意识的提升和对可持续发展的日益 重视, 将可再生天然聚合物作为催化剂的负载材料已变 得越来越重要. 其中, 纤维素是自然界中最丰富的可再 生天然聚合物, 可作为催化剂的有机载体 ${ }^{[1]}$. 纤维素具 有廉价易得、比表面积大、质轻及可生物降解特性等优 点, 是制备纳米复合材料的较佳生物质材料之一. 在纤
维素中，每个葡萄糖分子通过 $\beta-1,4-$ 糖苷键连接，葡萄 糖的二聚体是纤维二糖, 而纤维二糖的重复单元是纤维 素的主要组成部分(图 1) ${ }^{[2-3]}$. 其中, 分子内原子通过内 旋转构成分子链, 每条分子链通过氢键和范德华力相互 作用，并按一定的秩序堆砌形成晶胞单元. 这些单元具 有无定形的结晶区域，导致纤维间的作用力加强，可避

\footnotetext{
* Corresponding authors. E-mail: ccx0109@nefu.edu.cn; jspeng1998@nefu.edu.cn

Received July 28, 2020; revised October 23, 2020; published online November 18, 2020.

Project supported by the Natural Science Foundation of Heilongjiang Province (No. LC2018003), and the Fundamental Research Funds for the Central Universities (No. 2572019CG06).

黑龙江省自然科学基金(No. LC2018003)和中央高校基本科研业务费专项资金(No. 2572019CG06)资助项目.
} 
免与其他疏水性表面粘合，因此纤维素具有表面积高、 强度高、耐用性和生物相容性好等特点. 而且每个晶胞 单元中羟基的高活性使纤维素具有疏水性和手性 ${ }^{[4]}$. 其 中, 羟基可以通过部分或全部的羟基反应(如通过醚化、 羧甲基化、氰基乙基化和羟丙基化等反应)进行纤维素 的化学改性, 从而生成一些重要的纤维素衍生物(图 2). 由于性质改变, 所获得纤维素衍生物可能比纤维素更适 合用作有机催化剂的载体 ${ }^{[5-7]}$. 纤维素衍生物可根据取 代基及其合成方法的不同进行分类，例如通过酯化合成 酯一纤维素乙酸酯和通过醚化合成醚甲基纤维素或羧甲 基纤维素 ${ }^{[8]}$ 等. 在化学改性过程中, 水合氢离子渗透到 纤维素的无定形区域, 促进了糖苷键裂解, 导致含有活 性羟基的纤维素层次结构被破坏. 这些羟基和其他改性 后的官能团可与铜纳米颗粒进行静电作用, 进一步形成 纳米复合材料 ${ }^{[9]}$.

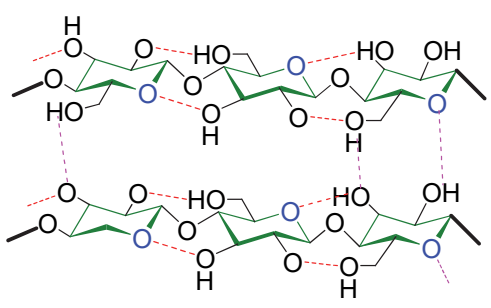

图 1 纤维素中的分子结构

Figure1 Molecular structure of cellulose

在当代有机化学领域中, 金属铜络合物具有毒性 低、价格便宜及反应条件温和等优点, 因此金属铜络合 物催化反应具有重要的意义, 但铜催化剂也存在自身的 缺点, 如使用寿命短、催化活性不高、选择性差、副反 应多以及催化剂无法回收而污染环境等. 为了有效抑制 铜的流失, 延长纤维素负载铜催化体系的使用寿命, 研
究铜催化剂的回收和再利用至关重要. 本综述强调了金 属铜纳米粒子负载纤维素催化剂的关键在于纤维素化 学修饰、功能化设计和回收再利用, 对近年来报道的纤 维素铜催化剂的制备及其参与的有机反应进行了归纳, 介绍了该类催化剂许多新颖的合成方法及对经典反应 的催化性能，希望为今后金属负载纤维素及其他生物聚 合物的合成和绿色应用提供参考.

\section{1 纤维素及其衍生物负载铜催化构建 C一X 键}

自纤维素被发现以来，纤维素及其衍生物的合成方 式层出不穷. 2000 年, Gauthier 课题组 ${ }^{[10]}$ 最先报道了金 属铜负载功能化纤维素的合成方法. 在此之后, 已有多 个课题组报道了纤维素负载铜材料的合成研究. 近年 来, $\operatorname{Kim}^{[11]}$, Norgren ${ }^{[12]}$, Amhamdi ${ }^{[13]}$, Tanskul ${ }^{[14]}$, Takemu$\mathrm{ra}^{[15]}$ 等课题组又相继报道了多种功能化纤维素铜络合 物的制备方法，意味着纤维素及其衍生物在不同类型反 应中的催化应用成为可能.

2006 年, Reddy 课题组 ${ }^{[16]}$ 报道了纤维素负载的 $\mathrm{Cu}(0)[\mathrm{Cell}-\mathrm{Cu}(0)]$ 催化剂的制备, 将 $\mathrm{Cu}\left(\mathrm{NO}_{3}\right)_{2} \cdot 3 \mathrm{H}_{2} \mathrm{O}$ 负 载在微晶纤维素上, 并将其用于咪唑与各种芳基卤化物 和芳基硼酸的 N-芳基化反应(Scheme 1), 无需使用额外 配体或添加剂的条件下获得了优秀的收率. 催化剂可通 过简单的过滤回收，并重复使用多次。其中，在咪唑与 碘苯的 Ullmann 反应中，催化剂经历四个循环后有 $3.5 \%$ 的铜浸出, 在咪唑与苯基硼酸的 Chan-Lam 反应中经过 四个循环后有 $5 \%$ 的铜浸出，同比负载前实现了催化剂 的多次循环利用.

同年，该课题组 ${ }^{[17]}$ 又将 $\mathrm{Cell}-\mathrm{Cu}(0)$ 催化剂用于 AzaMichael 反应, 使 $\mathrm{N}$-亲核试剂(胺和咪唑)与 $\alpha, \beta$-不饱和化 合物反应构建 $\mathrm{C}-\mathrm{N}$ 键, 以优异的产率得到相应的 $\beta$-氨

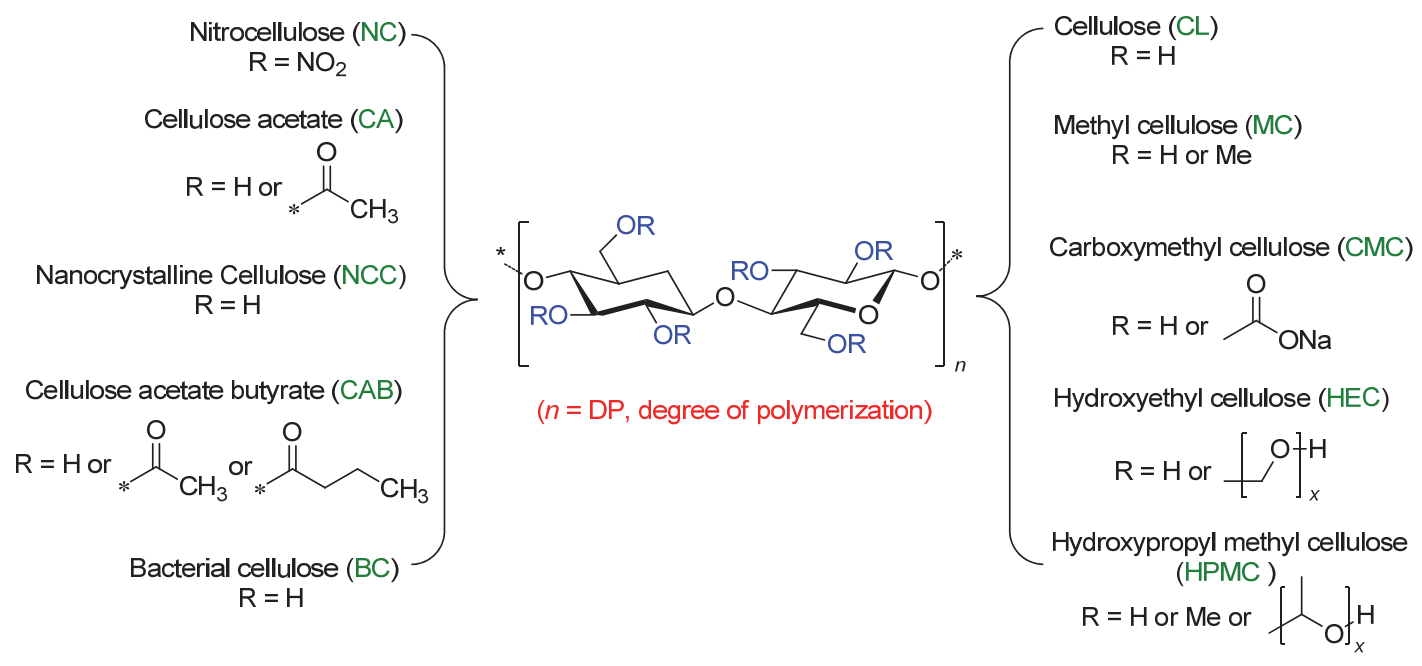

图 2 一些重要的纤维素及其衍生物

Figure 2 Some important cellulose and its derivatives 


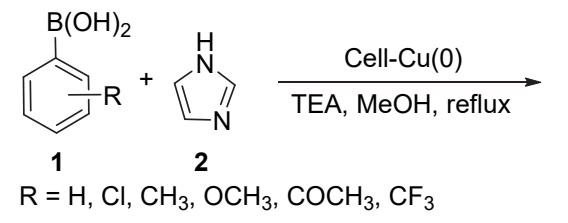<smiles>[X]c1cccc([R7]c2cnc(CCCCOC(C)=O)[nH]2)c1O</smiles>

图式 1 咪唑与芳基硼酸和芳基卤化物进行 $N$-芳基化反应 Scheme $1 \quad N$-Arylation of imidazole with aryl halides and arylboronic acids

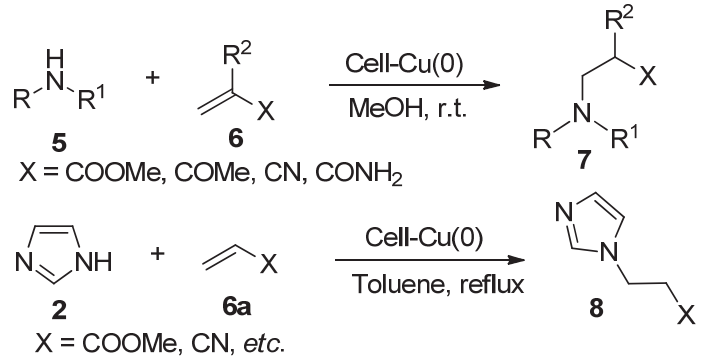

图式 $2 \alpha, \beta$-不饱和化合物的 Aza-Michael 反应 Scheme 2 Aza-Michael reaction of $\alpha, \beta$-unsaturated carbonyl compounds

基化合物和 $N$-取代咪唑(Scheme 2). 反应条件温和，回 收的催化剂活性稳定，可用于多次循环.

2010 年, 篗晓璐等 ${ }^{[18]}$ 采用 $\mathrm{Cell}-\mathrm{Cu}(0)$ 为催化剂, 在 不加入任何配体和氧化剂的条件下, 通过氮杂环与 4-溴 苯乙酮的 $\mathrm{C}-\mathrm{N}$ 偶联反应合成了化合物 4-氮杂环基苯乙 酮(产率 56.4\% 80.4\%), 然后其与多种取代苯甲醛进行 Claisen-Schmidt缩合反应得到一系列含氮杂环查尔酮衍 生物(产率为 49.3\% 90.2\%) (Scheme 3).

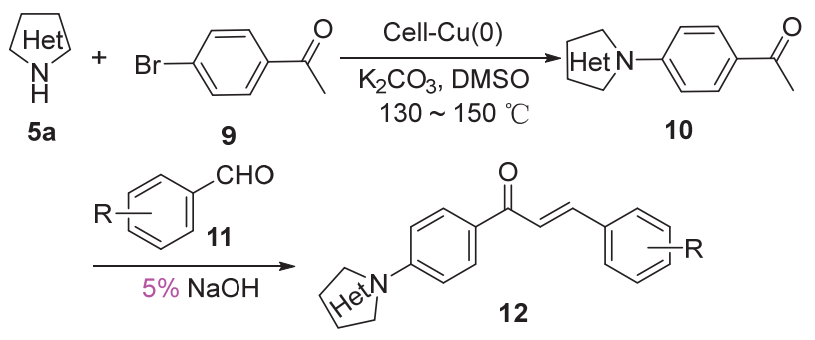

图式 3 合成查尔酮的 Claisen-Schmidt 缩合反应

Scheme 3 Claisen-Schmidt condensation reaction for synthesis of chalcone
2016 年, Sarkar 课题组 ${ }^{[19]}$ 制备了丙烯腈改性废弃玉 米芯纤维素表面上负载了 $\mathrm{Cu}$ 纳米颗粒 $(0.05 \mathrm{~mol} \%$ 至 50 mol ppm)的非均相催化剂(Scheme 4), 其能选择性地促 进脂肪胺的 Aza-Michael 反应(Eqs. 1, 2), 在室温下甲醇 中以高达 $95 \%$ 的产率得到相应的烷基化产物，具有高度 的区域选择性，负载的铜纳米粒子易于回收并重复使用 八次，而其活性不会显著降低.

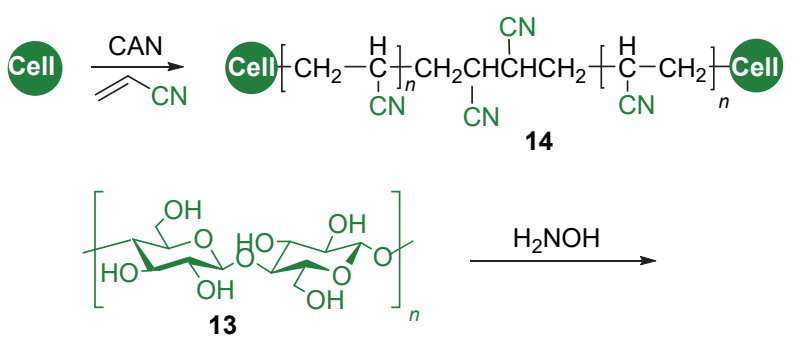

Waste corn-cob cellulose
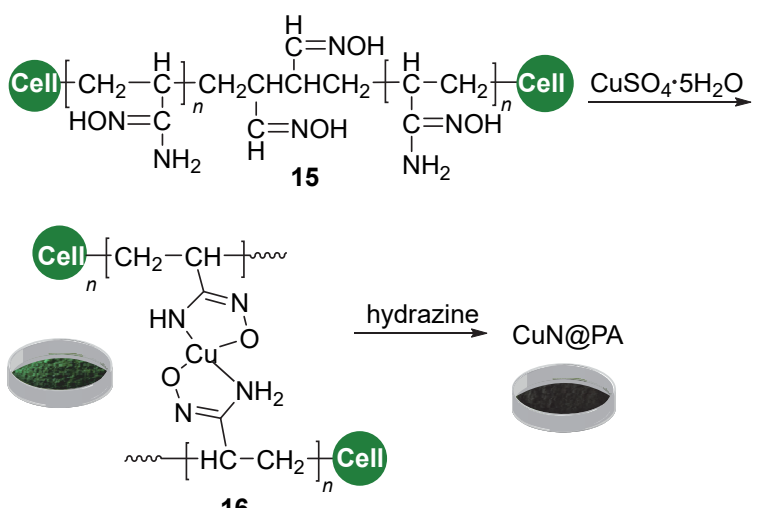

16

图式 4 废玉米芯纤维素负载的 CuN@PA 的合成

Scheme 4 Synthesis of waste corn-cob cellulose-supported CuN@PA

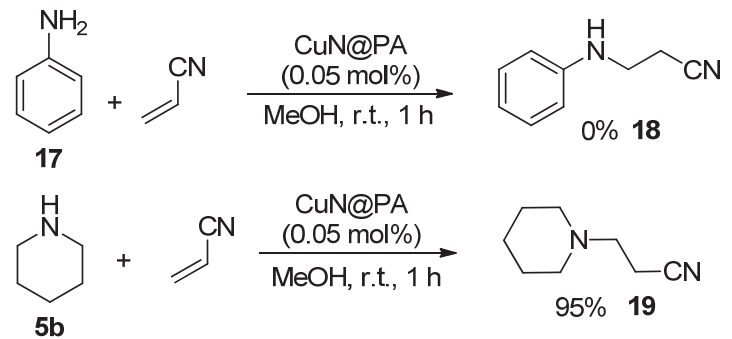

同年, 李毅群课题组 ${ }^{[20]}$ 开发了一种适用于醛、胺和 炔烃三组分反应(A3 偶联)的环保型 $\mathrm{Cu}$ (II)羧甲基纤维素 $(\mathrm{CMC})$ 催化剂, 并且可以使该反应在不加溶剂的情况下 以高产率制得各种炔丙基胺(Scheme 5). 随后，该课题 组在有氧条件下, 没有借助任何添加剂和碱的情况下实 现了芳族和脂族醛的制备，其反应过程中仅采用了 5 mol\% CMC-Cu(II), 就可以拥有较高的催化性能. 而且, 该催化剂易于回收和再利用，四个循环后其催化活性不 会显著降低. 与此同时，作者还对该纤维素铜催化剂参 
与的三组分反应机理进行了分析, 首先通过 CMC$\mathrm{Cu}(\mathrm{II})$ 激活炔烃进行去质子化后形成 $\mathrm{Cu}(\mathrm{II})$ 络合物 23a, 炔基铜中间体促进醛与胺加成消除获得亚胺 24a, 再配 位形成活化的 $\mathrm{Cu}(\mathrm{II})$ 络合物 $\mathbf{2 4 b}$, 炔基铜进一步对其亲 核进攻, 生成相应的炔丙基胺 22, 同时获得 $\mathrm{Cu}(\mathrm{II})$ 催化 剂进行循环(Scheme 6).
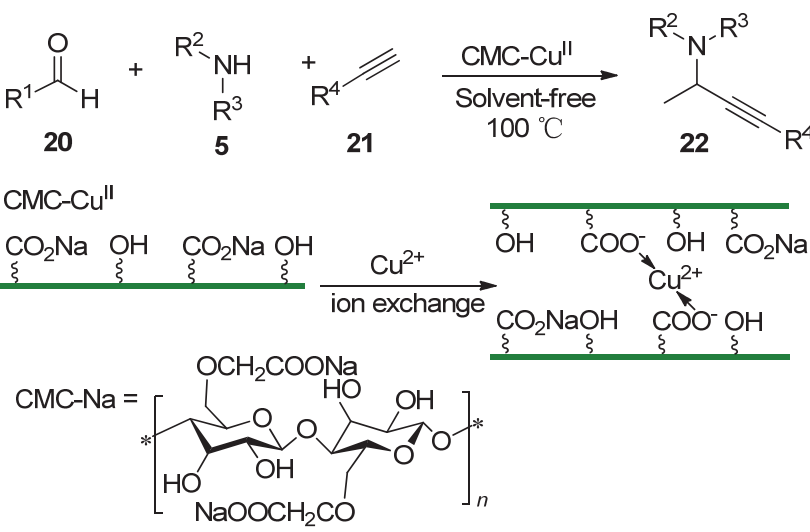

图式 $5 \mathrm{~A} 3$ 偶联反应及 $\mathrm{CMC}-\mathrm{Cu}(\mathrm{II})$ 催化剂的制备 Scheme 5 A3-coupling reaction and the preparation of CMC$\mathrm{Cu}(\mathrm{II})$ catalyst

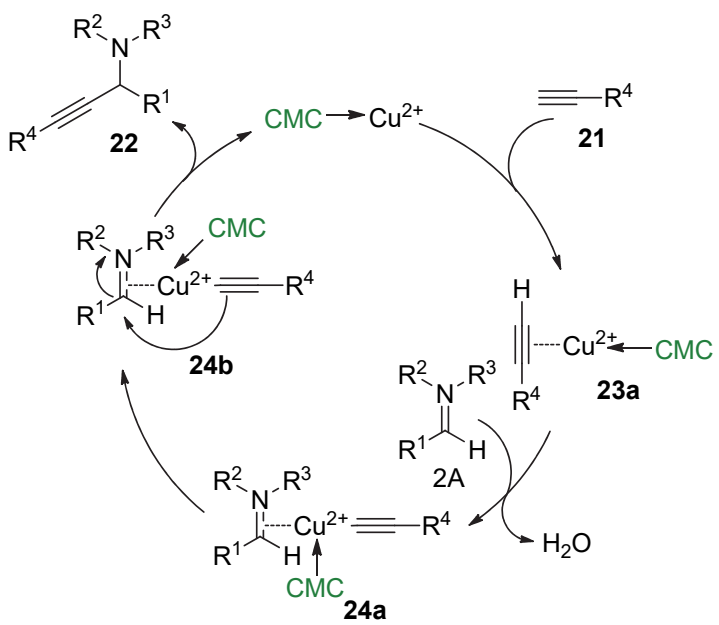

图式 $6 \mathrm{CMC}-\mathrm{Cu}(\mathrm{II})$ 参与的 $\mathrm{A} 3$ 偶联反应机理 Scheme 6 Proposed reaction mechanism for the A3-coupling involving $\mathrm{CMC}-\mathrm{Cu}(\mathrm{II})$

2017 年，姜玉钦等 ${ }^{[21]}$ 发现了一种在温和条件下， CMC-Cu(II)催化合成 1,3-二炔的新的有效途径(Eq. 3). 将该催化剂应用于各种末端炔烃的偶联反应中，经电感 耦合等离子体质谱仪(ICP-MS)测定, $\mathrm{CMC}-\mathrm{Cu}(\mathrm{II})$ 中负载 铜的质量分数为 $11.6 \%$, 从而提供了良好至优异的产物 收率, 并可以重复使用六次而不会损失催化活性. 作者 也提出了 $\mathrm{CMC}-\mathrm{Cu}(\mathrm{II})$ 参与 $\mathrm{C}-\mathrm{C}$ 偶联反应可能的机理 (Scheme 7).

同年, Martins 课题组 ${ }^{[22]}$ 对微晶纤维素进行修饰, 通 过 2,2,6,6-四甲基哌啶-1-氧基自由基(TEMPO)将伯羟基

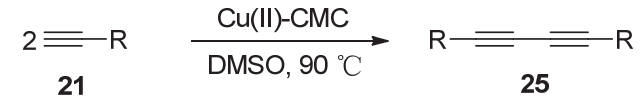

21

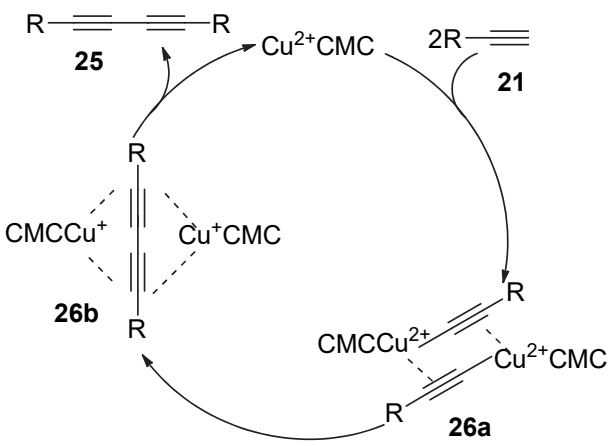

图式 $7 \mathrm{CMC}-\mathrm{Cu}(\mathrm{II})$ 参与的 $\mathrm{C}-\mathrm{C}$ 偶联反应机理 Scheme 7 Proposed reaction mechanism for the $\mathrm{C}-\mathrm{C}$ coupling involving $\mathrm{CMC}-\mathrm{Cu}(\mathrm{II})$

选择性地氧化为羧基，并将其用作非均质性配体与铜离 子配位合成新型的纤维素铜催化剂. 然后, 他们使用该 催化剂在不同条件下展开了 $\mathrm{C}-\mathrm{O}$ 偶联反应的尝试，结 果表明羧基纤维素基质作为 $\mathrm{C}-\mathrm{O}$ 偶联反应的配体均显 示出优异的催化效果, 而且醚副产物的形成能减至最少 $(<1 \%)$ (Eq. 4). 值得一提的是，该实验突出了羧基纤维 素在极性溶剂(如水和醇)中的亲和力以及在温和条件下 的应用，同样为 $\mathrm{C}-\mathrm{O}$ 键的形成构建了一个高效的环保 催化系统

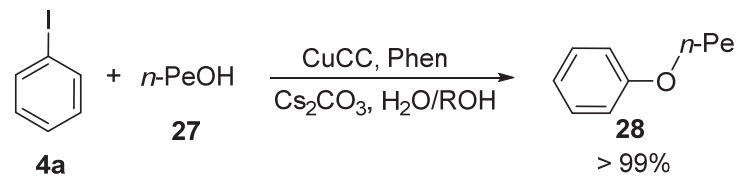

近年来, 磁性纤维素负载铜作为一种新型的多相纳 米催化剂走入了科研工作者的视野，该催化剂通过将不 同价态的铜衍生物和磁铁氧化物纳米颗粒沉积在化学 修饰后的纤维素上合成. 由于磁性纳米粒子可通过外部 磁体与反应混合物进行分离, 使纤维素铜催化剂的后处 理及回收利用优于其他催化剂. 2017 年, Shojaei 课题 组 ${ }^{[23]}$ 将 $\mathrm{CuI}$ 和 $\mathrm{Fe}_{3} \mathrm{O}_{4}$ 纳米颗粒负载到咪唑衍生物接枝的 纤维素上, 制备了 $\mathrm{CuI} / \mathrm{Fe}_{3} \mathrm{O}_{4} \mathrm{NPs} @ \mathrm{IL}-\mathrm{g}-\mathrm{Cs}$ 催化剂 (Scheme 8). 他们在实验过程中利用火焰原子吸收光谱 法(FAAS)对其进行表征，确定了负载在纳米催化剂中 的 $\mathrm{Cu}$ 和 $\mathrm{Fe}$ 离子的质量分数分别为 $5.37 \%$ 和 $20.23 \%$. 并 用该催化剂催化末端乙炔与磺酰基叠氮化物的反应，得 到高反应性的磺酰基亚胺中间体，之后，该中间体被仲 胺截留, 得到 $N$-磺酰脒和 $N$-磺酰基丙烯基脒产物. 该反 应是在室温无溶剂的条件下进行，且获得了极好的产率 $(88 \% \sim 92 \%)$ (Scheme 9). 实验表明该催化体系可以在 


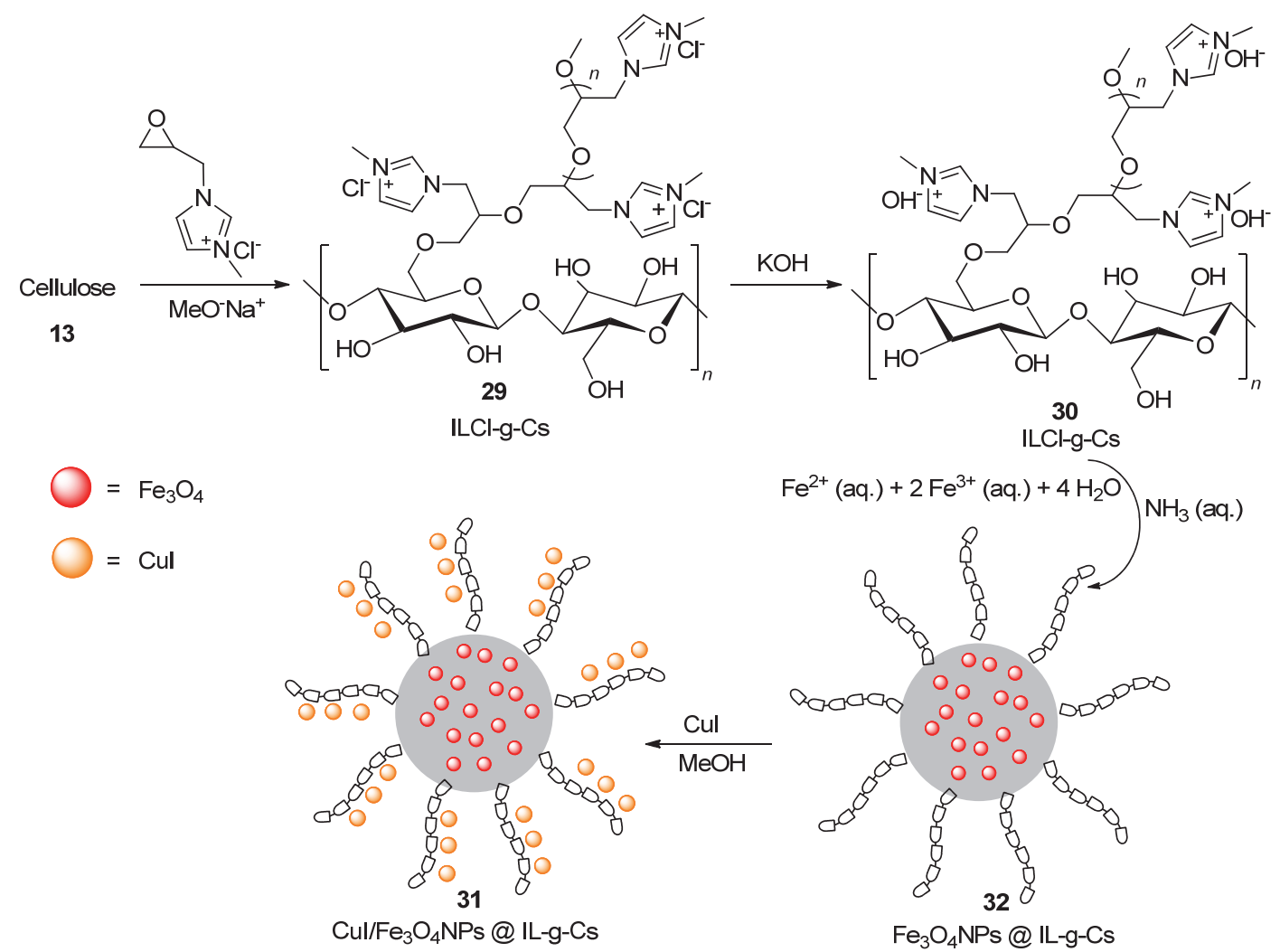

图式 $8 \mathrm{CuI} / \mathrm{Fe}_{3} \mathrm{O}_{4} \mathrm{NPs} @ \mathrm{IL}-\mathrm{g}-\mathrm{Cs}$ 催化剂的制备

Scheme8 Preparation of $\mathrm{CuI} / \mathrm{Fe}_{3} \mathrm{O}_{4} \mathrm{NPs} @ \mathrm{IL}-\mathrm{g}-\mathrm{Cs}$ catalyst
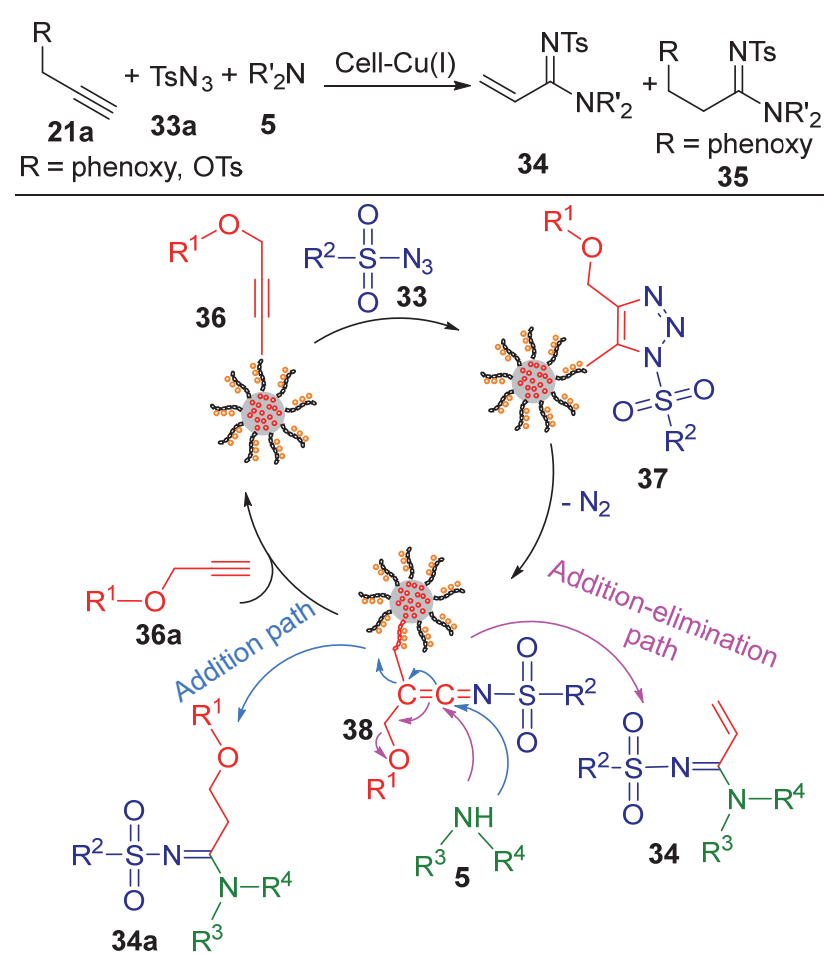

图式 $9 \mathrm{CuI} / \mathrm{Fe}_{3} \mathrm{O}_{4} \mathrm{NPs} @ \mathrm{Lg}-\mathrm{Cs}$ 催化合成 $N$-磺酰脒和 $N$-磺酰基 丙烯基脒

Scheme $9 \mathrm{CuI} / \mathrm{Fe}_{3} \mathrm{O}_{4} \mathrm{NPs} @ \mathrm{IL}-\mathrm{g}-\mathrm{Cs}$ catalyzed synthesis of $N$-sulfonylamidines and $N$-sulfonylacrylamidines
非常短的时间实现反应, 而且催化剂易于分离, 可重复 使用多次而催化活性又不显著降低.

此外, Shojaei 课题组 ${ }^{[24]}$ 又报道了NHC-Cu@MCs 催 化剂的另一种合成方法, 是将磁性纤维素(IL-g-MCs)连 同 $\mathrm{CuI}$ 和 $\mathrm{Na}^{+}$的悬浮液加入到四氢呋喃(THF)中, $60{ }^{\circ} \mathrm{C}$ 下剧烈搅拌 $8 \mathrm{~h}$ 制备. 通过进一步表征, 测定出纳米催 化剂中负载的 $\mathrm{Cu}$ 和 $\mathrm{Fe}$ 离子的质量分数分别为 $7.86 \%$ 和 $26.67 \%$, 他们利用该复合物催化了一个新的三组分反 应，合成了磺酰榺类衍生物(Scheme 10).

2019 年, Hamidi 课题组 ${ }^{[25]}$ 开发了一种新型的磁性 纤维素催化剂, 将 $\mathrm{FeCl}_{2}$ 和 $\mathrm{FeCl}_{3}$ 的混合离子液滴加到纤 维素上通过原位共沉淀法合成了 $\gamma-\mathrm{Fe}_{2} \mathrm{O}_{3}$ 纳米粒子负载 纤维素(Scheme 11). 他们将其应用到二氢吡啶和多氢喹 啉的合成，取得较高的收率，可以通过控制三组分在反 应中的比例, 进而实现产物的高选择性. 作者对该反应 的机理也做了简单的概述，如 Scheme 12 所示: 芳香醛 47 与二甲酮 49 或 1,3-酮酸酯 48 之间发生缩合反应形成 中间体 53. 然后, 将 52 或 $\mathbf{5 2 a}$ 再加到 53 中产生中间体 54. 随之, $\mathrm{NH}_{4} \mathrm{OAc}$ 对 54 的羰基亲核进攻生成中间体 56 . 最后, 进行亚胺一烯胺互变异构转换, 得到最终产物 $\mathbf{5 8}$ 或 $58 \mathrm{a}$.

2018 年, Das 等[26]报道了一种环境友好型一步合成 

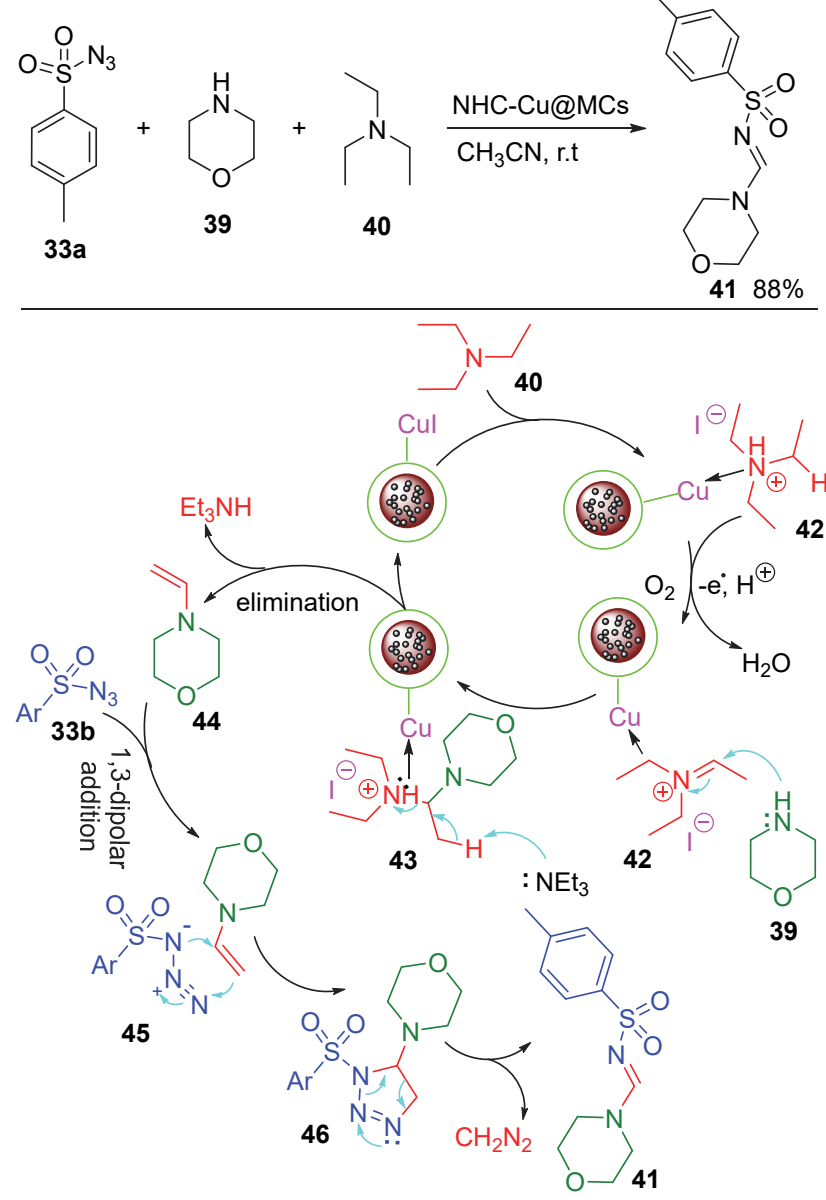

图式 10 三组分反应合成磺酰榺类衍生物

Scheme 10 Three-component synthesis of $N$-sulfonylformamidines

纳晶纤维素负载铜纳米粒子的新方法(Scheme 13). 从 芙蓉的内茎提取纤维素, 并通过化学还原法将其制备. 实验得到了平均粒径为 $7 \mathrm{~nm}$ 的球形纳米颗粒, 并将其 用于环仲胺和缺电子乙烯基化合物的 $\mathrm{C}-\mathrm{N}$ 偶联反应 (Scheme 14). 催化剂不仅显示出优异的收率 $(82 \%$
95\%), 且能循环使用六个周期，催化活性也没有任何明 显的损失.

2019 年, Runic 课题组 ${ }^{[27]}$ 采用了一种先进的生物材 料细菌纳米纤维素(BNC)作铜的载体, BNC 具有纤维素 的所有基本特征，例如高强度轻巧、可定制的表面积、 亲水性和生物降解性等. $\mathrm{BNC}$ 可从多种碳源(包括来自 草类生物质水解的糖)中获得，该小组利用麦德林曲霉 ID13488 菌株发酵提取, 所得的 BNC 直接用于催化剂制 备(Scheme 15). 实验表明催化剂中负载的铜的质量分 数为 $3 \%$, 其催化 Chan-Lam 偶联反应得到良好的产率, 而且可再生的 BNC 基质使催化剂更易于分离和再利用 (Eq. 5).<smiles>NCc1ccccc1</smiles>

63<smiles>Oc1ccccc1</smiles>

1

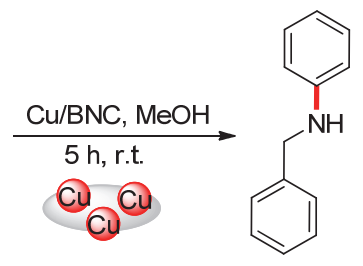

64

\section{2 纤维素及其衍生物负载铜催化的环加成反应}

Sharpless ${ }^{[28]}$ 在 2001 年开辟了以碳-杂原子键 $(\mathrm{C}$ $\mathrm{X}-\mathrm{C}$ )合成为基础的组合化学新方法, 并借助这些反应 (点击反应)来简单高效地获得多样性的分子, 在药物合 成及生物材料制备领域均取得不错的进展. 其中的代表 反应为铜催化的叠氮 - 炔基 Husigen 环加成反应 (Copper-catalyzed azide-alkyne cycloaddition). 近来年, 多个课题组相继报道了纤维素负载铜催化剂在点击反 应中的应用.

2012 年, Kitaoka 课题组 ${ }^{[29]}$ 将一价铜离子 $\mathrm{Cu}(\mathrm{I})$ 负载 到具有大量羧酸钠的 TEMPO 氧化过的纤维素纳米纤维 (TOCNs) 晶体表面上, 通过 $\mathrm{Na}$ 和 $\mathrm{Cu}$ 粒子之间的离子交 换，在其表面形成基团. 随后经过冷冻干燥处理，将载
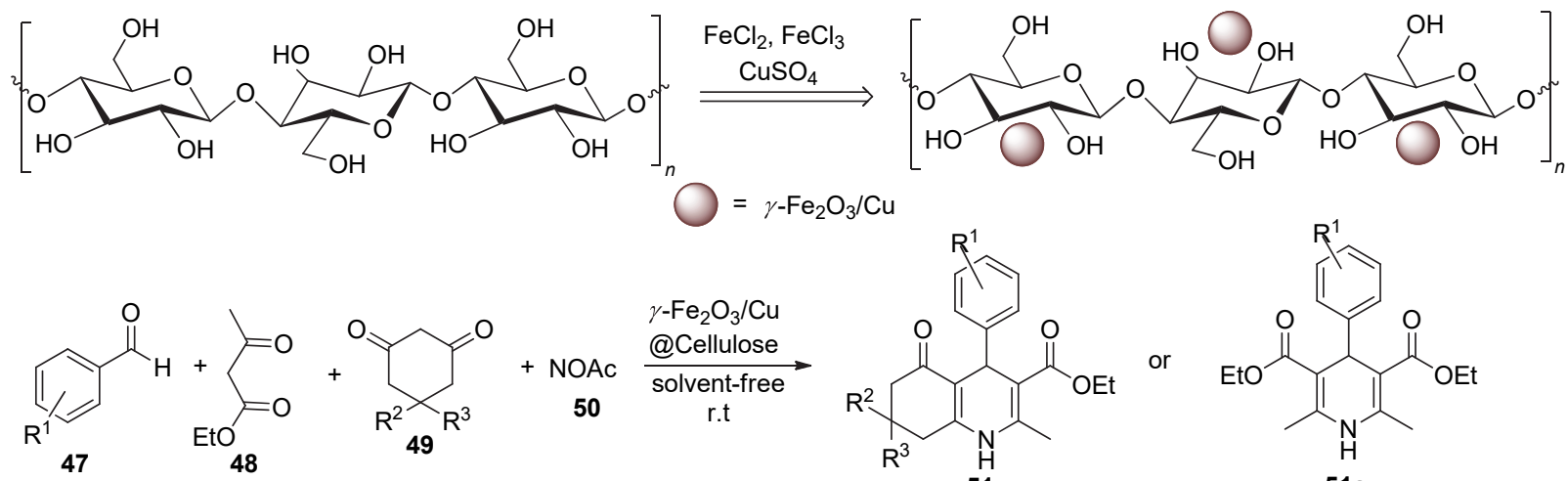<smiles>[R]C1([R])CC(=O)C2=C(C1)NC(C)=C(C(=O)OCC)C2c1ccc[R1]([H])c1</smiles><smiles>CCOC(=O)C1=C(C)NC(C)=C(C(=O)OCC)C1c1cc[R](C)cc1</smiles>

图式 $11 \gamma-\mathrm{Fe}_{2} \mathrm{O}_{3} / \mathrm{Cu} @$ Cellulose 催化二氢吡啶和多氢喹啉的合成 Scheme11 Synthesis of dihydropyridines and polyhydroquinolines using $\gamma-\mathrm{Fe}_{2} \mathrm{O}_{3} / \mathrm{Cu} @$ Cellulose as a catalyst 


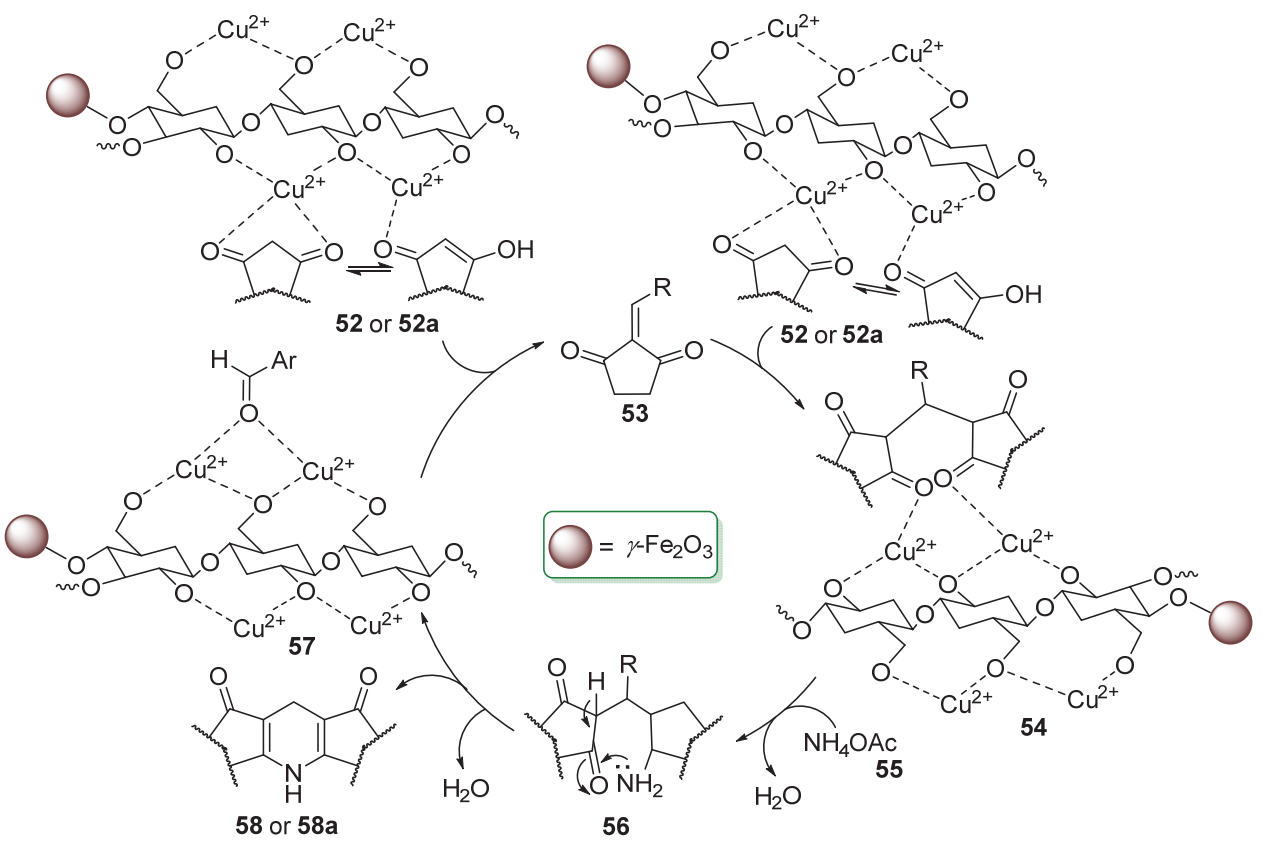

图式 12 二氢吡啶和多氢喹啉的合成机理

Scheme12 Proposed mechanism for the synthesis of dihydropyridine and polyhydroquinoline derivatives
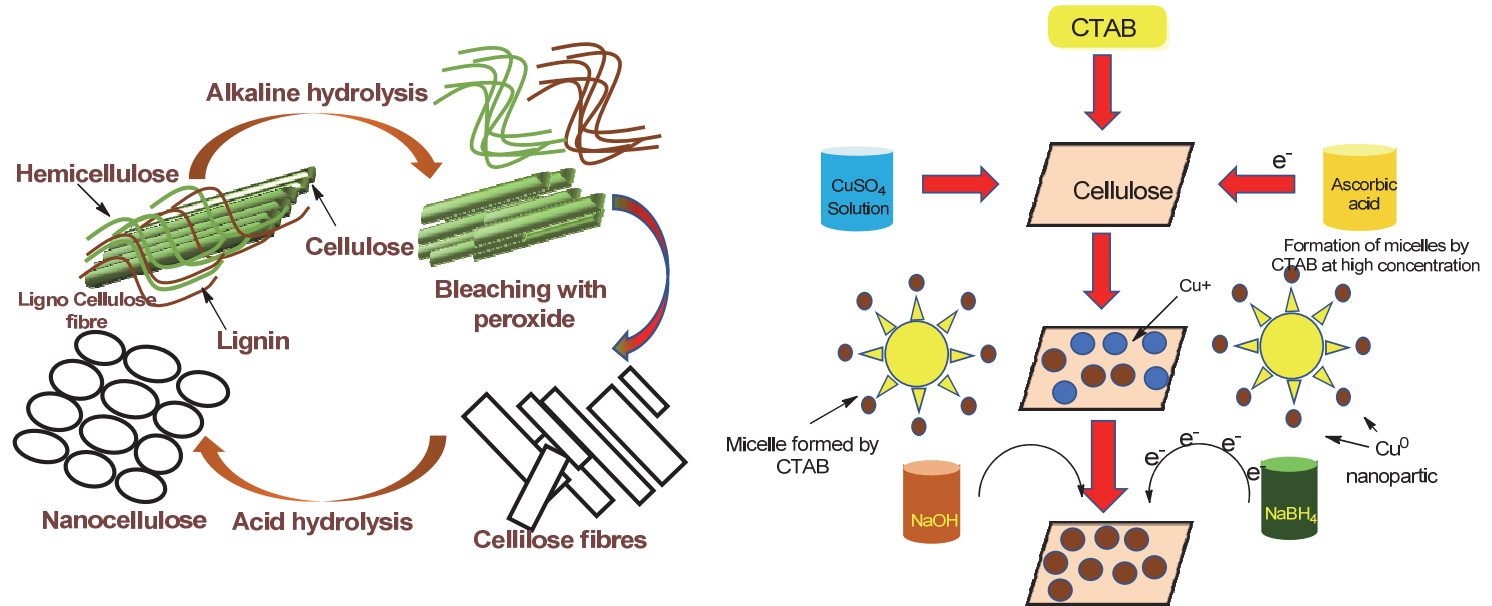

图式 13 纳晶纤维素负载的铜纳米粒子的合成

Scheme 13 Synthesis of the cellulose-supported copper nanoparticles

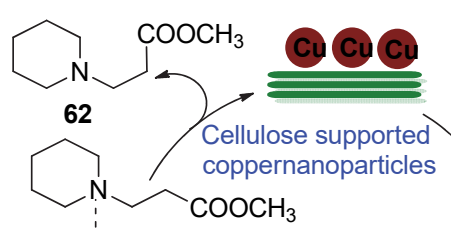

cycact

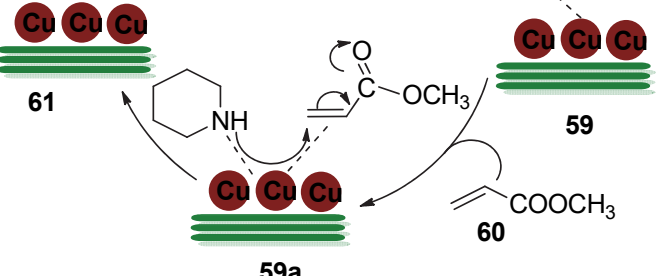

$59 a$

图式 14 丙烯酸甲酯和哌啶之间的 $\mathrm{C}-\mathrm{N}$ 偶联反应的机理图 Scheme 14 Mechanistic view of the $\mathrm{C}-\mathrm{N}$ coupling reaction between methyl acrylate and piperidine

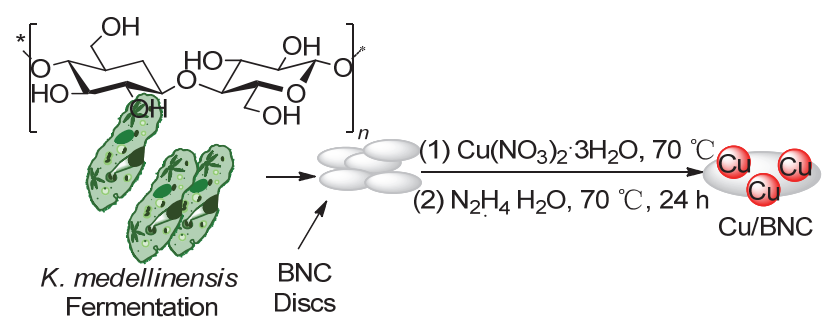

图式 15 细菌纳米纤维素(BNC)负载铜纳米颗粒

Scheme 15 Bacterial nanocellulose (BNC)-supported copper nanoparticles

有铜的 TOCNs 制成气凝胶. 制备的 $\mathrm{Cu}-\mathrm{TOCN}$ 气凝胶对 叠氮化物-炔烃的 Huisgen [3+2]环加成反应表现出优 异的催化效率, 表明 $\mathrm{Cu}(\mathrm{I})$ 催化剂高度分散并暴露在结 
晶 TOCN 的整个表面上, 能有效与反应物接触(Scheme 16). $\mathrm{Cu}-\mathrm{TOCN}$ 气凝胶可从反应系统中回收, 并且在反 应过程中将 $\mathrm{Cu}(\mathrm{I})$ 离子广泛地分布在 $\mathrm{TOCN}$ 上. 因为 TOCN 可以很容易地从天然纤维素中获得. 因此, $\mathrm{Cu}(\mathrm{I})-\mathrm{TOCN}$ 是一种高性能且环境友好的催化剂.

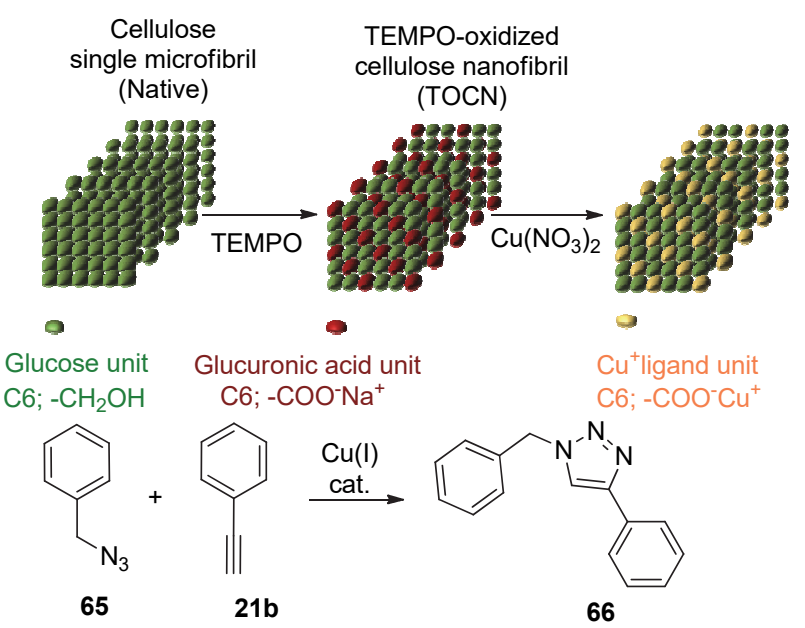

图式 $16 \mathrm{TOCNs}$ 上负载 $\mathrm{Cu}(\mathrm{I})$ 离子和 Huisgen [3+2]环加成反 应

Scheme 16 Topological loading of $\mathrm{Cu}(\mathrm{I})$ ions on crystalline TOCNs and Huisgen [3+2] cycloaddition

2014 年, Wadgaonkar 课题组 ${ }^{[30]}$ 首次将纤维素负载 的碘化亚铜纳米颗粒(Cell-CuI NPs)作用在芳基、烷基溴 化物、炔烃和叠氮化钠之间，此反应体系在水中通过一 锅法点击合成 1,4-二取代的 1,2,3-三唑(Eq. 6). 他们发现 Cell-CuI NPs 催化剂可以重复使用五次, 而活性不会有 明显的降低. 在整个反应体系中, 原料炔烃和叠氮化物 之间发生的是热诱导 1,3-偶极环加成反应. 作者也提出 了相应的机理(Scheme 17).

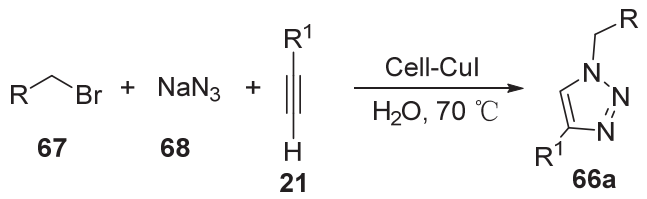

2015 年, Habibi 课题组 ${ }^{[31]}$ 通过咪唑鎓盐改性后的纤 维素负载碘化铜 $(\mathrm{CuI})$ 纳米颗粒制备了新型的纤维素铜 (NHC)络合物(Scheme 18). 研究表明该催化剂可以促进 烷基/苄基卤化物或甲苯磺酸盐与末端炔烃和叠氮化钠 在水中进行一锅反应, 通过 1,3 偶极环加成得到 1,2,3三唑偶联产物(Eq. 7). 另外, 该反应中催化剂表现出优 良的循环性能，能简便地回收并重复使用七次，且催化 活性没有显著损失.

2016 年, 章鹏飞课题组 ${ }^{[32]}$ 报道了非均相催化剂 Cell- $\mathrm{Cu}(0)$ 在水中催化糖基叠氮化物和炔烃以良好至优
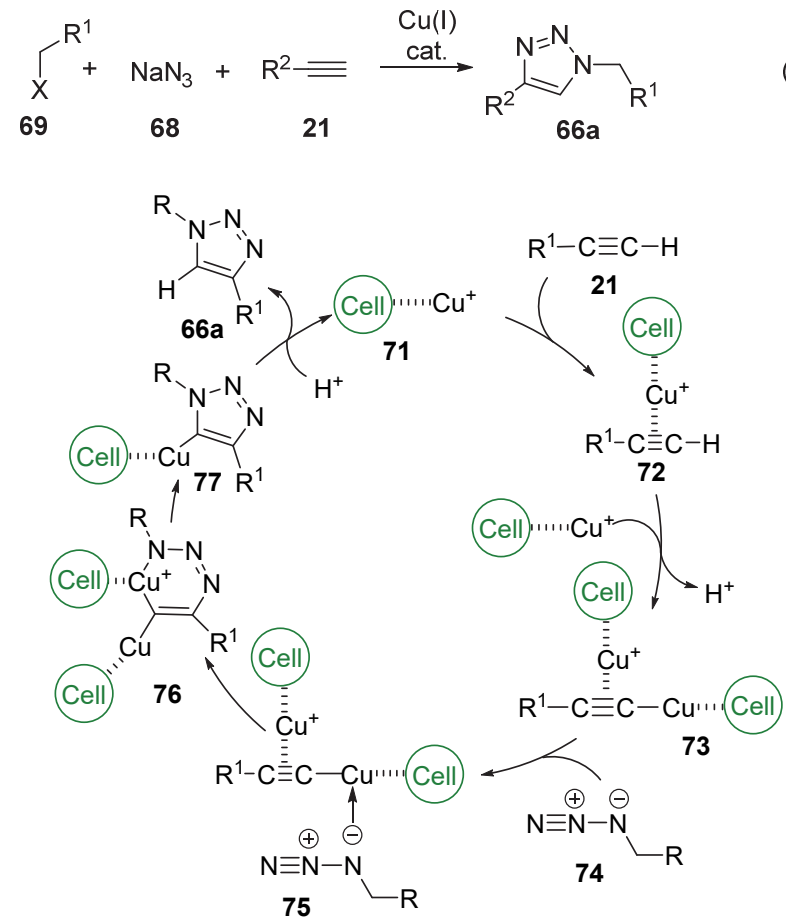

图式 $17 \mathrm{Cell}-\mathrm{Cu}(\mathrm{I})$ 催化合成 1,2,3-三唑的机理

Scheme 17 Mechanism of cell-Cu(I) catalysed synthesis of 1,2,3-triazoles
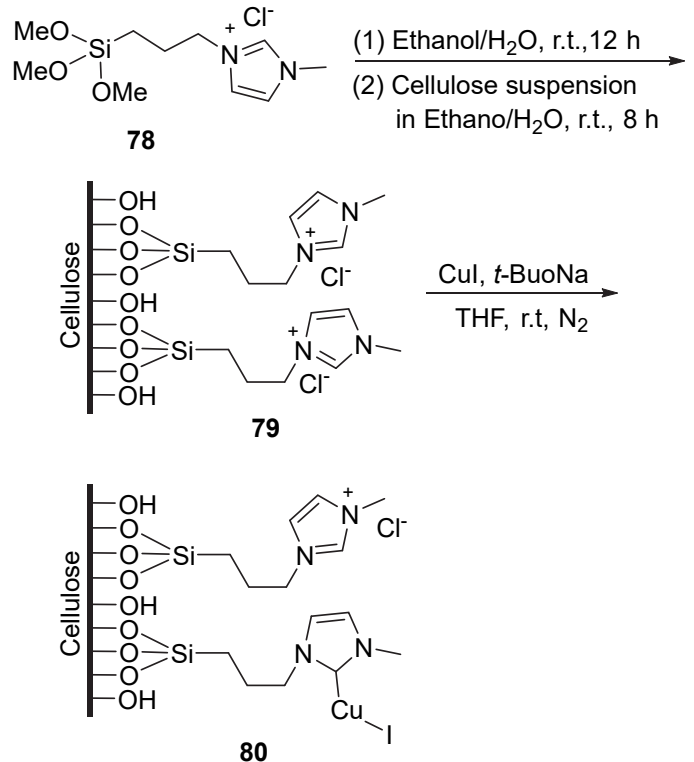

图式 $18 \mathrm{NHC}-\mathrm{Cu} / \mathrm{CL}$ 的制备示意图

Scheme 18 Schematic description for the preparation of $\mathrm{NHC}-\mathrm{Cu} / \mathrm{CL}$

异的产率合成 $N$-糖基-1,2,3-三唑(Scheme 19). 其中，反 应过程里添加的的催化剂是采用上文中 Reddy 小组报 道的 $\mathrm{Cell}-\mathrm{Cu}(0)$. 与 $\mathrm{Cu}$ 负载前相比, $\mathrm{Cell}-\mathrm{Cu}(0)$ 在该反 应中具有高催化性和低铜浸出率的优点，底物炔烃可以 兼容各种官能团，催化剂的分离和再利用也是简单而高 效的. 
(A)

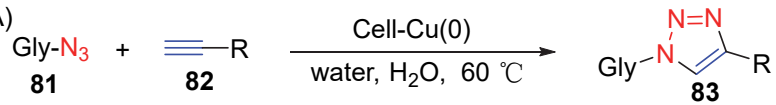

(B)

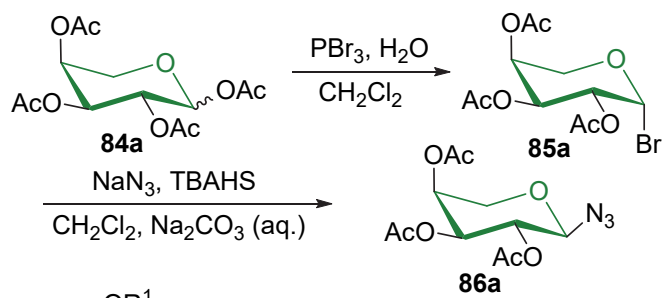

(C)

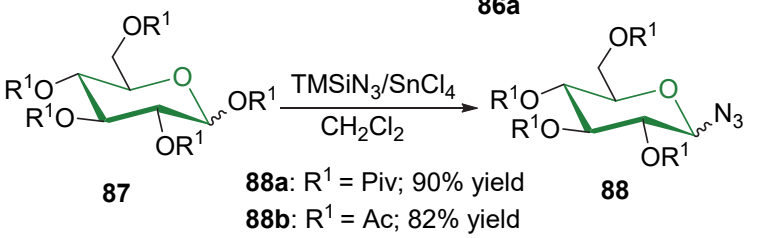

图式 19 (A) Cell- $\mathrm{Cu}(0)$ 催化糖基叠氮化物和末端炔烃的环加 成及(B)阿拉伯吡喃基叠氮化物和 $(\mathrm{C})$ 吡喃葡萄糖基叠氮化物 的合成

Scheme 19 (A) Cellulose- $\mathrm{Cu}(0)$ catalyzed the cycloaddition of glycosyl azides and terminal alkynes, (B) synthesis of arabinopyranosylazide and $(\mathrm{C})$ glucopyranosyl azide

2016 年, Felpin 等 ${ }^{[33]}$ 报道了一种改性后的纤维素仿 生还原剂, 由硫醇改性后制备了 Cell-SH, 然后该还原 系统进一步与 $\mathrm{CuSO}_{4} \cdot 5 \mathrm{H}_{2} \mathrm{O}$ 水溶液接触后, 在几秒钟内 将 $\mathrm{Cu}(\mathrm{II})$ 还原为 $\mathrm{Cu}(\mathrm{I})$ 得到新的一价纤维素铜催化剂 $\left(\mathrm{Cu}_{2} \mathrm{O} \mathrm{NP} / \mathrm{Cell}-\mathrm{SH}\right)$, 经研究证明最初可以载入 $95 \%$ 含量 的铜. 他们将该催化剂用于催化炔烃和有机叠氮化物的 $[3+2]$ 环加成反应并吸附反应溶液中的残留铜粒 (Scheme 20). 该催化体系与水性条件兼容, 对位阻和各 种官能团具有良好的耐受性, 并且对 1,4-三唑的区域选 择性极好. 因此, 不仅以优异的产率高效地制备了多种 唑类衍生物, 而且强大的铜吸附力便捷了后处理的过 程，也实现了该催化剂多次的循环利用.
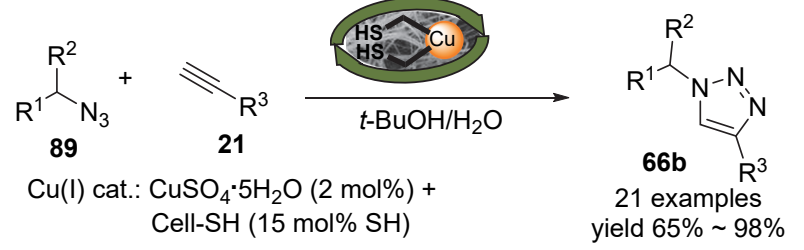

图式 $20 \mathrm{Cu}(\mathrm{I}) / \mathrm{Cell}-\mathrm{SH}$ 催化 Huisgen $[3+2]$ 环加成反应 Scheme $20 \mathrm{Cu}(\mathrm{I}) / \mathrm{Cell}-\mathrm{SH}$ catalyzed Huisgen $[3+2]$ cycloaddition reaction

2017 年, Sarkar 等 ${ }^{[34]}$ 又在氮气氛围下, 以硝酸铈铵 (CAN)为引发剂, 通过洋麻纤维素与丙烯酸甲酯的共聚 反应, 合成了纤维素聚丙烯酸酯, 后与盐酸差胺的甲醇 水溶液混合进行改性, 制备纤维素席夫碱铜催化剂 (Scheme 21). 该催化剂不仅有效地实现了 Click 反应, 而且适用于多种官能团取代的叠氮化物, 并且 1,2,3-三
唑的产率高达 94\% (Eq. 8). 催化剂可以在六次循环中完 全再生且产率没有明显的降低. 此外, Sarkar 课题组 ${ }^{[32]}$ 在近几年间还实现了木薯纤维素负载铜纳米颗粒催化 1,2,3-三唑的合成.

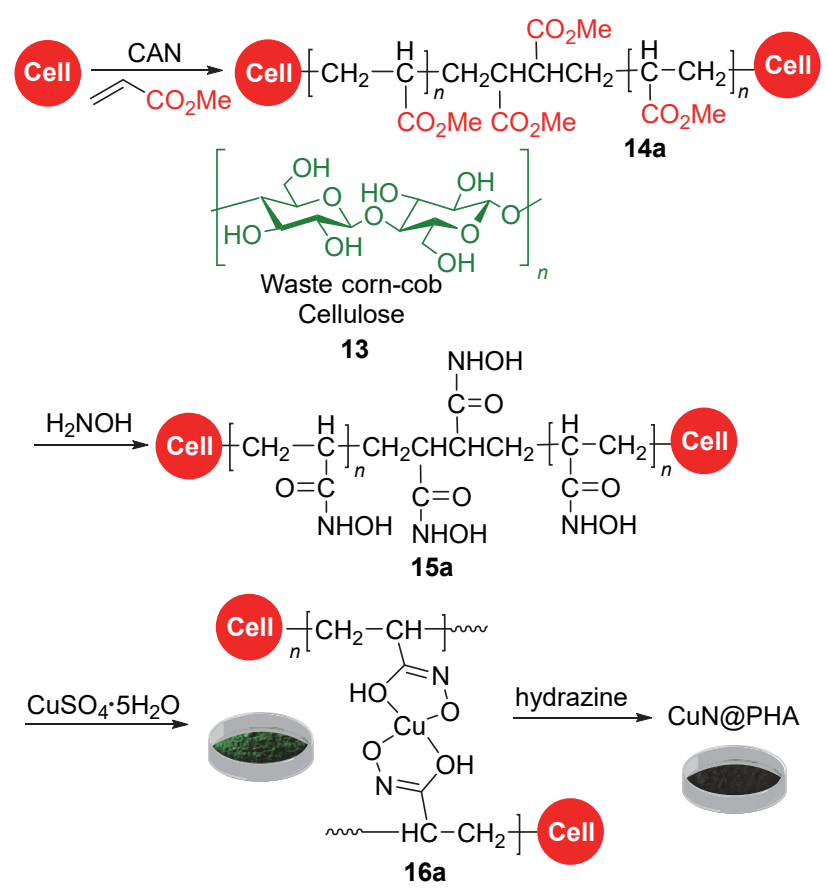

图式 21 洋麻纤维素负载的 $\mathrm{CuN} @$ PHA 的制备

Scheme 21 Preparation of Kenaf bio-cellulose-supported CuN@PHA

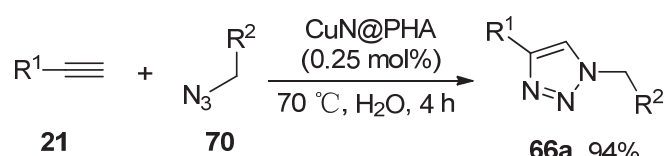

2018 年, Stiriba 课题组 ${ }^{[36]}$ 以从菄椰树中提取纤维素 负载 $\mathrm{Cu}(\mathrm{I})$ 或 $\mathrm{Cu}(\mathrm{II})$ 离子作催化剂, 并在室温下区域选择 性地合成了 19 种 1,4-二取代的 1,2,3-三唑衍生物, 收率 在 $82 \%$ ～97\% (Eq. 9). 实验证明㫫椰树纤维素铜络合物 能更加稳定地催化产物的合成, 值得一提的是, 该催化 剂可重复使用五次且通过简单的过滤即可分离.

$$
\begin{aligned}
& \text { Cellulose as biological macromolecule } \\
& \text { for click chemsitry }
\end{aligned}
$$

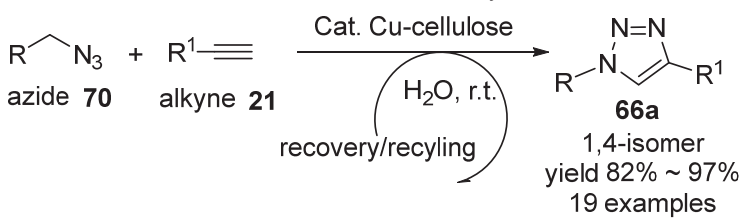

2019 年, Pandoli 课题组 ${ }^{[37]}$ 利用微反应器技术(MRT) 首次完成了以龙竹竹杆制备铜功能化木质纤维素 $(\mathrm{Cu}-\mathrm{L} \mu \mathrm{R})$ (Scheme 22), 并将其用于催化叠氮化物和末 端炔烃之间的 1,3-偶极环加成( $\mathrm{CuAAC})$ 反应，反应以中 
等到优异的收率(60\%～96\%)得到产物(Eq. 10). 该技术 明显地提升了整个催化体系的反应选择性和适用性. 且 该催化体系在第五次循环中, 其催化效率仍可维持在 $73 \%$, 从而证明了新型功能化木质纤维素铜催化体系的 持续合成潜力.

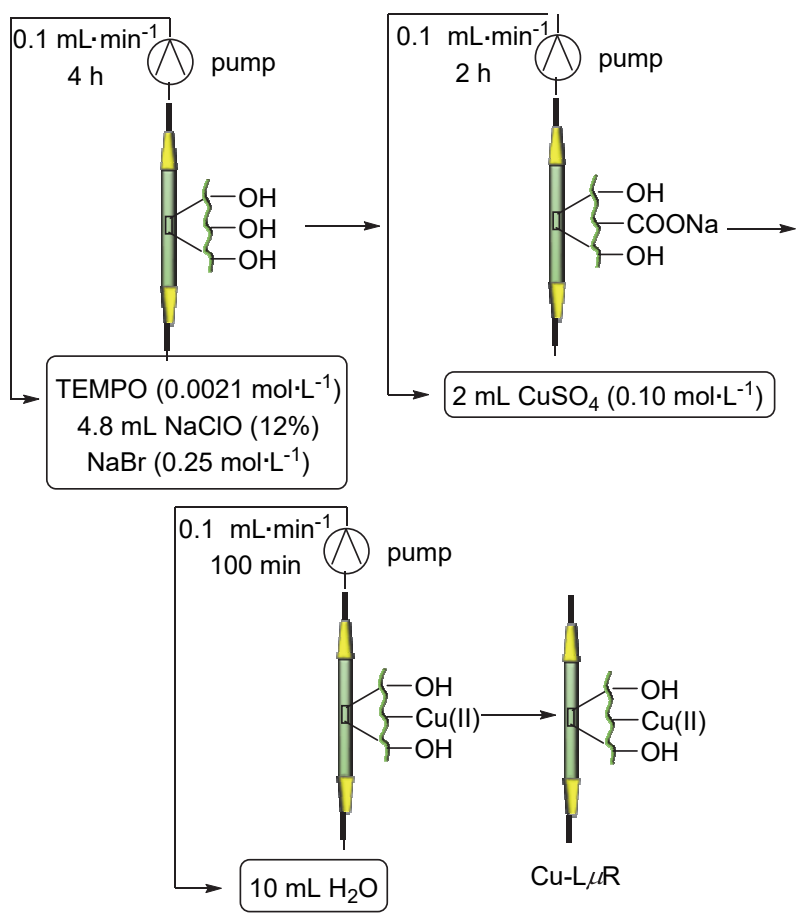

图式 22 龙竹功能化 $\mathrm{Cu}-\mathrm{L} \mu \mathrm{R}$

Scheme 22 Dendrocalamus giganteus Munro functionalized $\mathrm{Cu}-\mathrm{L} \mu \mathrm{R}$

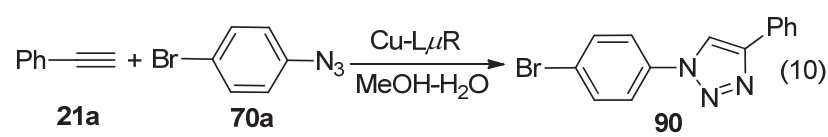

2020 年, Shahverdizadeh 课题组 ${ }^{[38]}$ 报道了一种新的 球型的纤维素-铜(II)氧化物复合颗粒, 他们将纤维素通 过 Schweizer 试剂改性后, 发现 $\mathrm{CuO}$ NPs 均匀分布在纤 维素颗粒上, 然后在室温条件下进行透析法制备. 同时 也运用了 X 射线衍射、扫描电子显微镜、过渡电子显微 镜、能量色散 X 射线光谱、热重分析及电感耦合等离子 体发射光谱等技术表征了这种新型的纤维素铜络合物, 实验结果表明颗粒为球形, 尺寸均匀, 平均直径约为 $500 \mathrm{~nm}$, 在水中具有良好的分散能力. 随后, 他们检测 了该非均相催化剂在水中进行点击反应的效果, 并得到 了 $87 \%$ 的收率(Scheme 23).

\section{3 纤维素及其衍生物负载铜催化的氧化反应}

2015 年, Konwar 课题组 ${ }^{[39]}$ 报道了纤维素负载 $\mathrm{Cu}$ 纳 米颗粒可在微波辐射下, 乙腈/水溶剂中对各种茮醇、肉 桂醇和杂芳基醇进行有效和选择性的氧化, 使其生成相

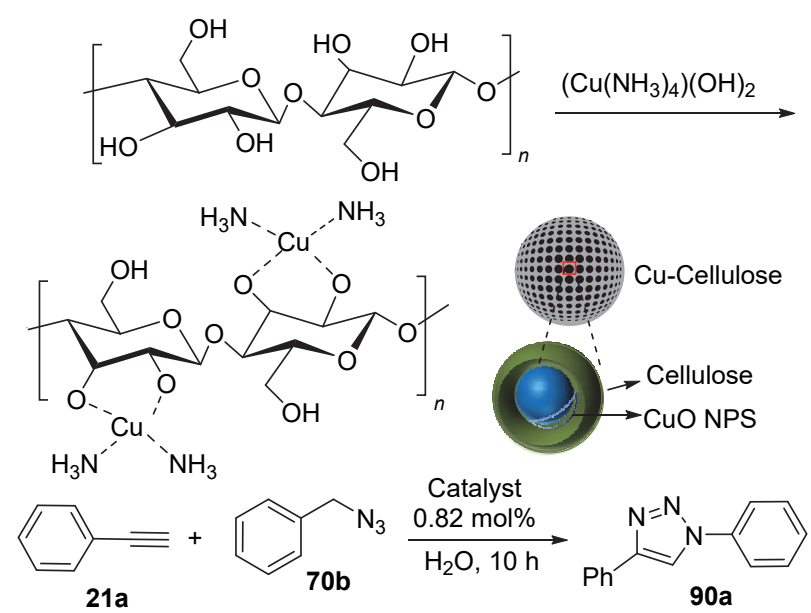

图式 $23 \mathrm{Cell} / \mathrm{Cu}$ 的制备及催化点击反应

Scheme 23 Preparation of $\mathrm{Cell} / \mathrm{Cu}$ and catalyzed click reaction

应的醛, 其中氧气是唯一氧化剂(Eq. 11). 过程中催化剂 表现出相应的选择性, 使反应往伯醇基被氧化的方向进 行，而仲醇基没有变化，不会发生醛酮氧化成酸或其他 物质的转变. 实验证明该系统相较于之前的催化体系具 有绿色、方便、高化学选择性、反应时间短和后处理简 便等优点.

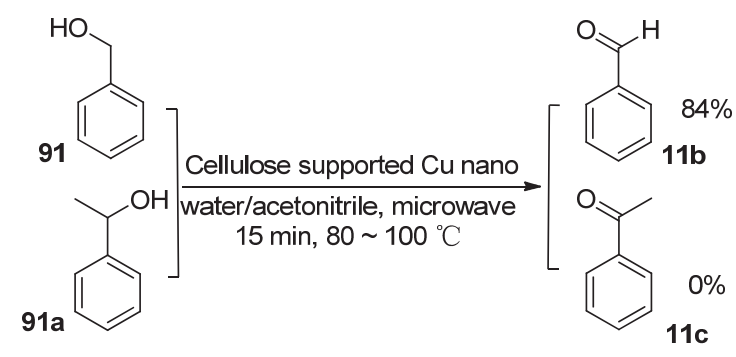

同年，Yan 等 ${ }^{[40]}$ 发现了一种新的环保型非均相催化 剂(Scheme 24), 将四磺酸酞菁铜负载在纤维素纳米晶 体上，并将其用于在水中催化醇和芳基芳烃的选择性氧

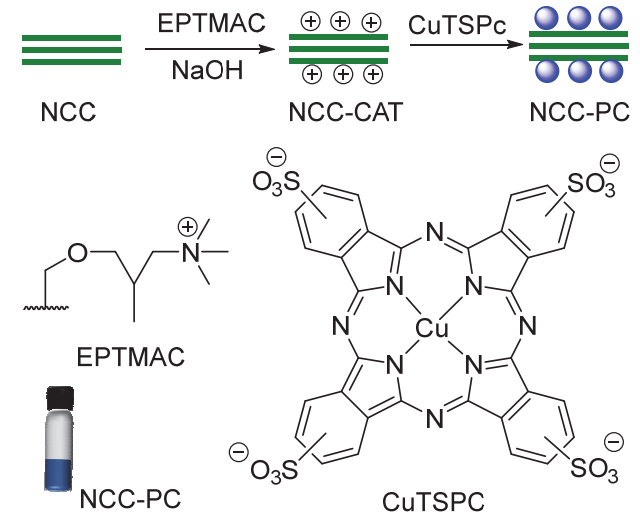

图式 24 酞菁改性纳米晶纤维素

Scheme 24 Grafting of phthalocyanine on crystalline nanocellulose 
化(Eq. 12). 反应非常顺利, 在室温下以 $99 \%$ 的极好收率 获得产物, 而且催化剂可以实现多次循环使用. 酞菁基 大环附着在铜纳米颗粒上, 赋予铜纳米颗粒光物理、光 电和催化性能, 与纤维素结合成功克服了后处理条件繁 琐以及回收催化剂困难的问题.

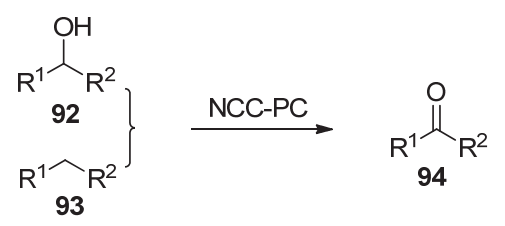

此外, Shaabani 课题组 ${ }^{[4]}$ 也合成了具有 $\mathrm{Cu}(\mathrm{II})$ 的四 氨基和四硫代酞菁的功能化纤维素 CuTAPc@Cell 和 CuTSPc@Cell, 并将其用于催化烷基芳烃和醇的氧化反 应(Scheme 25). 他们研究发现从溶剂、转化率、温度和 反应时间的角度来看, 最好的催化剂是 CuTSPc@Cell, 不仅以极好的收率得到相应的产物( $99 \%)$, 还很容易地 回收利用, 并重复使用时效率不会明显降低.

2018 年, Nekouei 等 ${ }^{[22]}$ 报道了一种新型的功能化纤 维素催化剂, 首先他们从番茄皮中提取纤维素并加工成 纤维素纳米晶体, 再用乙二胺将其改性, 然后通过溶剂 热法合成分层花状的 CuS 空心纳米球(Scheme 26), 制备 $\mathrm{CuS}$ 负载的胺化纤维素材料. 实验研究表明该催化体系
在过氧一硫酸盐(PMS)存在下, 对环丙沙星(CIP)具有很 高的催化氧化降解效率. 其中, CuS@CNCs 催化 CIP 的 降解速度是仅使用 PMS 时的 68 倍, 关键原因是催化过 程中会产生・OH 自由基和 $\mathrm{SO}_{4}{ }^{-}$自由基, 从而加快 $\mathrm{CIP}$ 的氧化(Scheme 27).

2019 年, Sarma 课题组 ${ }^{[43]}$ 报道了在纤维素纳米晶体 上负载铜纳米颗粒能可控并有选择性地将硫化物氧化 为亚砜, 将伯醇氧化为醛(Eqs. 13, 14). 对芳香族、脂肪 族和杂环硫化物, 该催化体系都可以高产率地将它们氧 化成相应的亚砜, 而且不会形成过氧化的砜. 类似地, 芐基、烯丙基和脂族醇被选择性地氧化成醛，而且没有 羧酸生成, 产率良好至优异. 该小组为了评估其可重复 使用性，通过简单过滤将催化剂分离，用水和丙酮洗涤 数次, 然后在相同条件下进一步添加适量底物后即用于 下次运行. 经过热过滤实验，发现没有 $\mathrm{Cu}$ 浸出到反应 混合物中，证明该催化剂可多次循环使用.

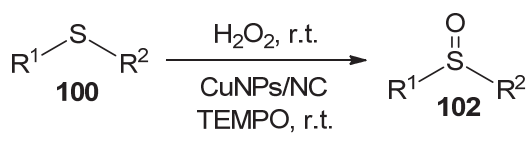

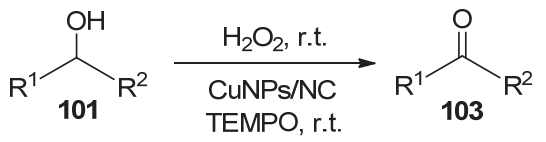
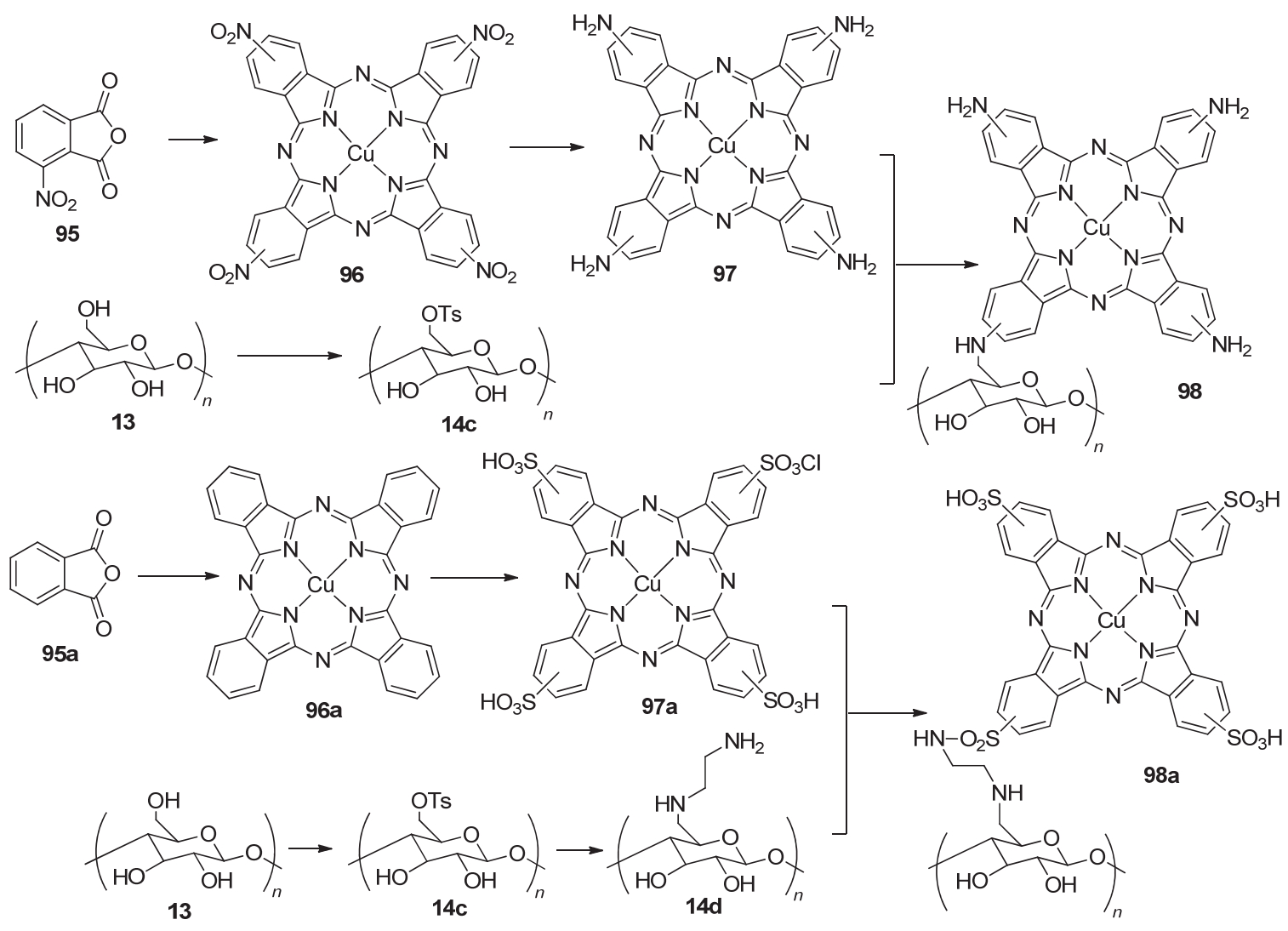

图式 25 四氨基和四硫代酞菁功能化纤维素的制备

Scheme 25 Preparation of functionalized cellulose with tetra-amino and tetra-thiophthalocyanine 


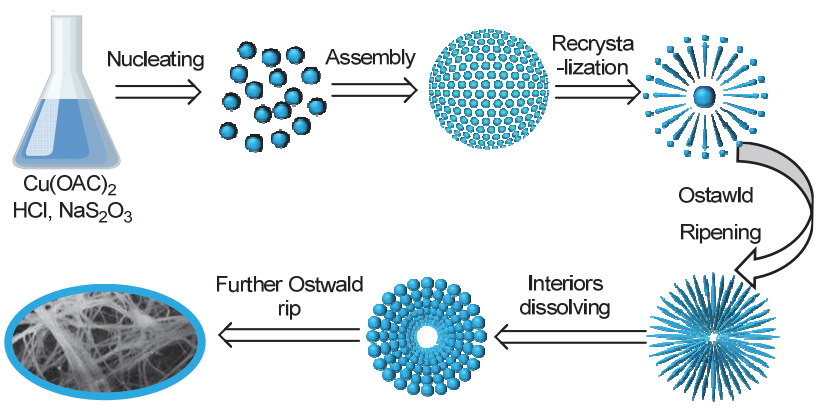

图式 $26 \mathrm{CuS}$ 空心纳米球的形成

Scheme 26 Formation of CuS hollow nanospheres

(a)

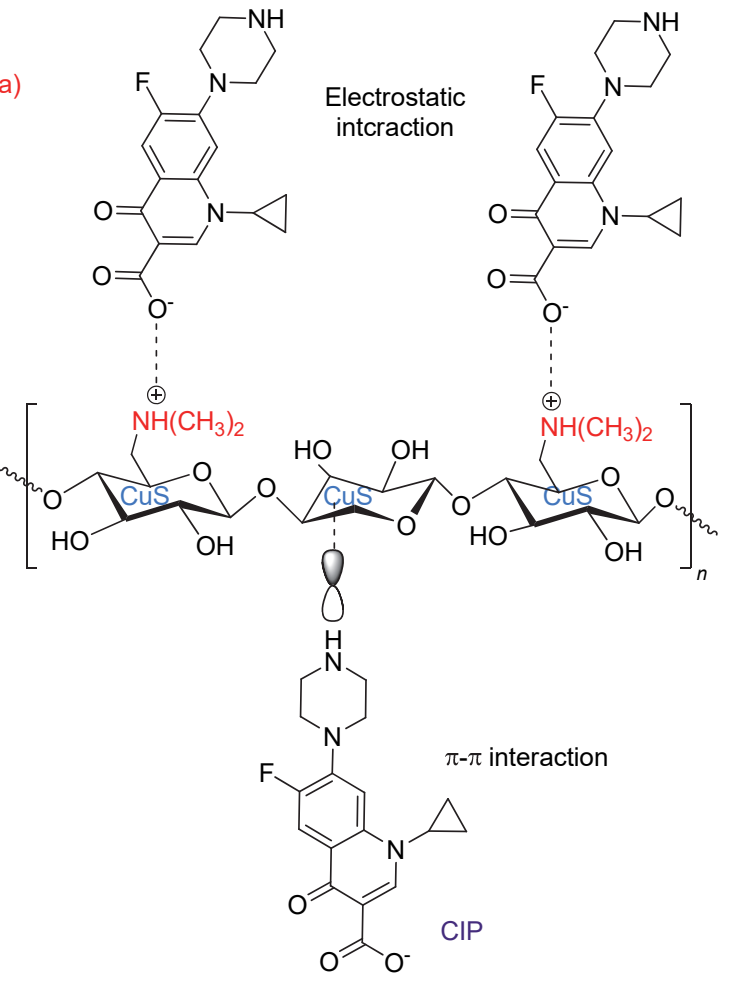

\section{4 纤维素及其衍生物负载铜催化的还原反应}

2002 年, Shim 课题组 ${ }^{[4]}$ 将铜络合物直接掺入乙酸 纤维素(CA)中, 所得的乙酸铜络合物质量分数为 $5 \%$ $20 \%$, 在 $25 \sim 160{ }^{\circ} \mathrm{C}$ 的之间纤维素型铜络合物不仅可以 与 $\mathrm{CO}, \mathrm{H}_{2}, \mathrm{D}_{2}, \mathrm{O}_{2}, \mathrm{NO}$, 烯烃等小分子气体发生作用,而 且还能够和羰基衍生物以及各种氢化物配位, 从而促进 反应的发生。实验中发现该络合物在烯烃和 $\mathrm{CH}_{3} \mathrm{CN}$ 的 加氢反应显示出较好的催化活性，也能在相对温和的条 件下催化 NO 气体的还原反应，一氧化碳气体以及羰基 的氧化反应. 值得一提的是, 乙酸铜络合物在高达 $200{ }^{\circ} \mathrm{C}$ 的温度下具有热稳定性. 在加热过程中，乙酸铜 络合物主要分解为 $\mathrm{Cu}_{2} \mathrm{O}$ 和 $\mathrm{CH}_{3} \mathrm{COOCu}$, 但在 $200{ }^{\circ} \mathrm{C}$ 以 下，除脱水以外，不会因为铜络合物分解而损失.

2013 年, 张新星课题组 ${ }^{[45]}$ 在纤维素纳米晶体 (CNs)中引入氧化铜纳米粒子 $(\mathrm{CuO} N \mathrm{NPs})$ (Scheme 28). 由于 $\mathrm{CNs}$ 的高表面积和大量的羟基诱导，使得 $\mathrm{CNs}$ 负载 的 $\mathrm{CuO} N \mathrm{NP}$ 纳米杂化物非常稳定, 即便一个月后, $\mathrm{CuO}$ $\mathrm{NPs} / \mathrm{CNs}$ 悬浮液仍保持良好的分布. 所获得的纳米杂化 物在 4-硝基苯酚的催化还原中表现出比未负载的和其 他材料负载的 $\mathrm{CuONPs}$ (例如氧化石墨烯负载的 $\mathrm{CuO}$ )更 高效的催化活性.

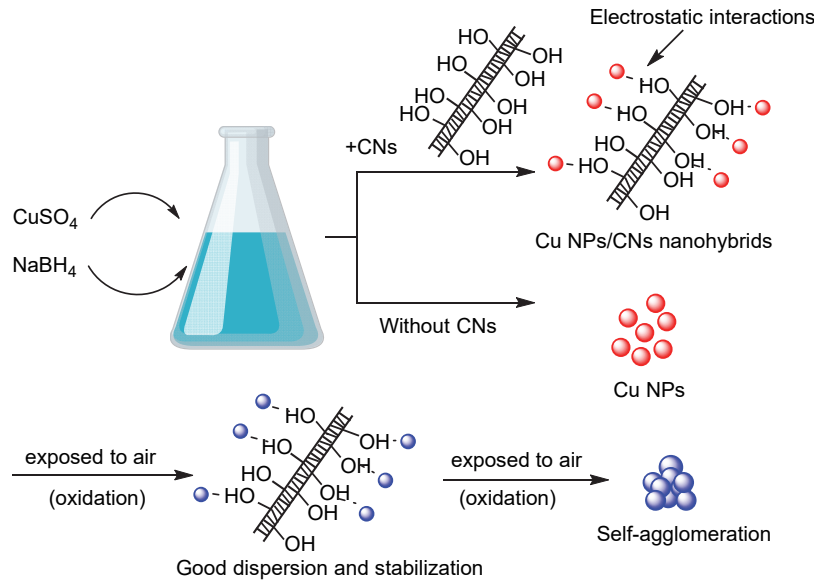

图式 $28 \mathrm{CNs}$ 作为 $\mathrm{CuO} \mathrm{NPs}$ 的负载材料和稳定剂的示意图 Scheme 28 Schematic illustration using CNs as supporting materials and stabilizer for $\mathrm{CuO}$ NPs

2015 年，李洪亮课题组 ${ }^{[46]}$ 将喷雾干燥技术与煅烧 相结合，制备了具有独特芝麻球结构的纤维素铜碳复合 微粒(CCMs) (Scheme 29). 首先将纤维素溶解在铜氨溶 液中获得铜氨纤维素络合物溶液，再经过喷雾干燥法合 成 $\mathrm{Cu}\left(\mathrm{NH}_{3}\right)_{4}^{2+}$ /纤维素络合物微粒, 然后将得到的复合 物在 450 或 $550{ }^{\circ} \mathrm{C}$ 下煅烧原位转化为分布均匀的 $\mathrm{Cu}$ 颗 粒状多孔碳球. 他们通过研究 $\mathrm{Cu}\left(\mathrm{NH}_{3}\right)_{4}^{2+}$ 与纤维素大分 子羟基之间的配位作用, 发现 $\mathrm{Cu}$ 颗粒在 $\mathrm{CCMs}$ 中的分 散能力极好. 在温和条件下, 以 $\mathrm{NaBH}_{4}$ 作还原剂, $\mathrm{CCMs}$ 
对 4-硝基苯酚(4-NP)转化为 4-氨基苯酚(4-AP)的反应中 显示出高效的催化性能(Eq. 15).

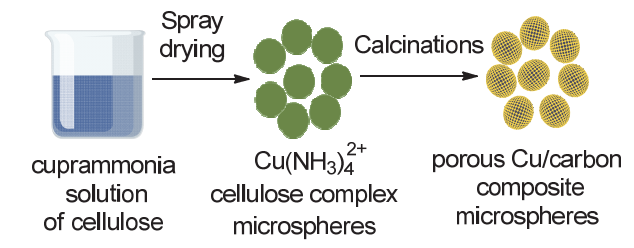

图式 $29 \mathrm{CCMs}$ 的制备

Scheme 29 Preparation of CCMs

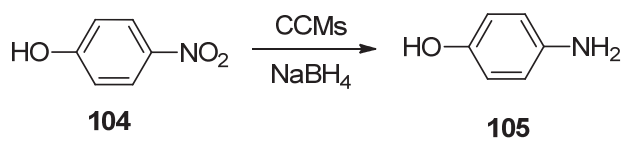

2017 年, Khan 课题组 ${ }^{[47]}$ 采用一种非常简单且低成 本的方法在纯醋酸纤维素 $(\mathrm{CA})$ 和醋酸纤维素-铜氧化物 $(\mathrm{CA}-\mathrm{CuO})$ 的表面上合成了有效的铜 $(\mathrm{Cu})$, 银 $(\mathrm{Ag})$ 和铜银 $(\mathrm{Cu}-\mathrm{Ag})$ 混合纳米颗粒复合材料. 负载在 $\mathrm{CA}$ 和 $\mathrm{CA}-\mathrm{CuO}$ 上的所有纳米颗粒均具有出色的催化能力, 尤 其是负载在 $\mathrm{CA}-\mathrm{CuO}$ 上的 $\mathrm{Cu}-\mathrm{Ag}$ 纳米颗粒 $(\mathrm{Cu}-\mathrm{Ag} / \mathrm{CA}-\mathrm{CuO})$ 表现出优异的催化能力, 可将 4-NP 转 化为 4-AP. 其中, 硝基苯酚溶液在紫外灯 $317 \mathrm{~nm}$ 处显 示出强吸收, 并在加入 $\mathrm{NaBH}_{4}$ 时发生红移至 $400 \mathrm{~nm}$, 形 成了 4-硝基苯酚盐离子而使颜色从浅黄色变为深黄色, 然后在 $\mathrm{Cu}-\mathrm{Ag} / \mathrm{CA}-\mathrm{CuO}$ 的催化下, 硝基酚酸根离子(400 $\mathrm{nm}$ )的吸收带被完全忽略, 并且在 $295 \mathrm{~nm}$ 出现了新的吸 收，这归因于 4-氨基苯酚的生成，导致 4-硝基苯酚盐溶 液由黄色变为无色(Scheme 30). 此外, 在反应介质中除 去薄片, 可以容易地回收 $\mathrm{Cu}-\mathrm{Ag} / \mathrm{CA}-\mathrm{CuO}$, 并且能够循 环四次以上.

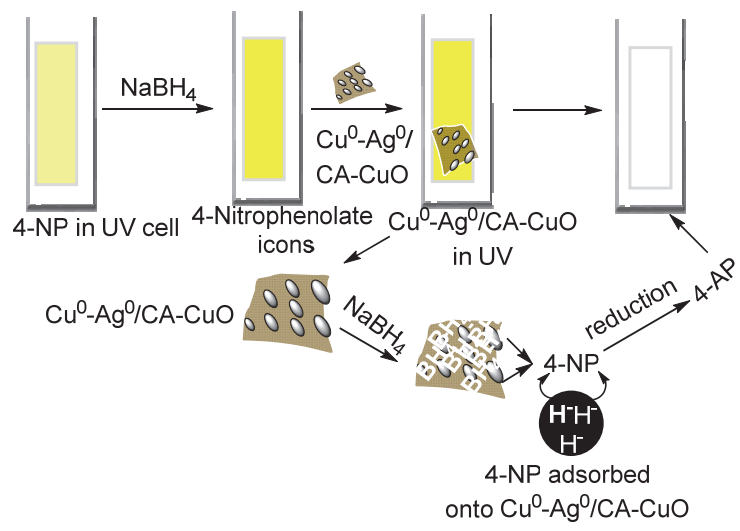

图式 30 4-NP 转化为 4-AP 的机理图

Scheme 30 Mechanism for the conversion of 4-NP to 4-AP

2019 年, Godiya 等 ${ }^{[48]}$ 制备了一种新型的生物质水凝 胶, 其中含有羧甲基纤维素(CMC)和聚丙烯酰胺(PAM). 合成的 $\mathrm{CMC} / \mathrm{PAM}$ 复合物显示出对 $\mathrm{Cu}(\mathrm{II})$ 离子强大的亲 和力, 根据 Langmuir 吸附模型及其吸附的平衡数据证
明 $\mathrm{Cu}^{2+}$ 离子最大吸附量为 $227.3 \mathrm{mg} / \mathrm{g}$. 然后, 将水凝胶 中吸附的 $\mathrm{Cu}(\mathrm{II})$ 离子原位还原形成均匀分散的 $\mathrm{Cu}$ 纳米 颗粒，从而制备负载有 $\mathrm{Cu} N \mathrm{NP}$ 的 $\mathrm{CMC} / \mathrm{PAM}$ 水凝胶，并 实现了 4-NP 到 4-AP 的高效转化(Scheme 31).
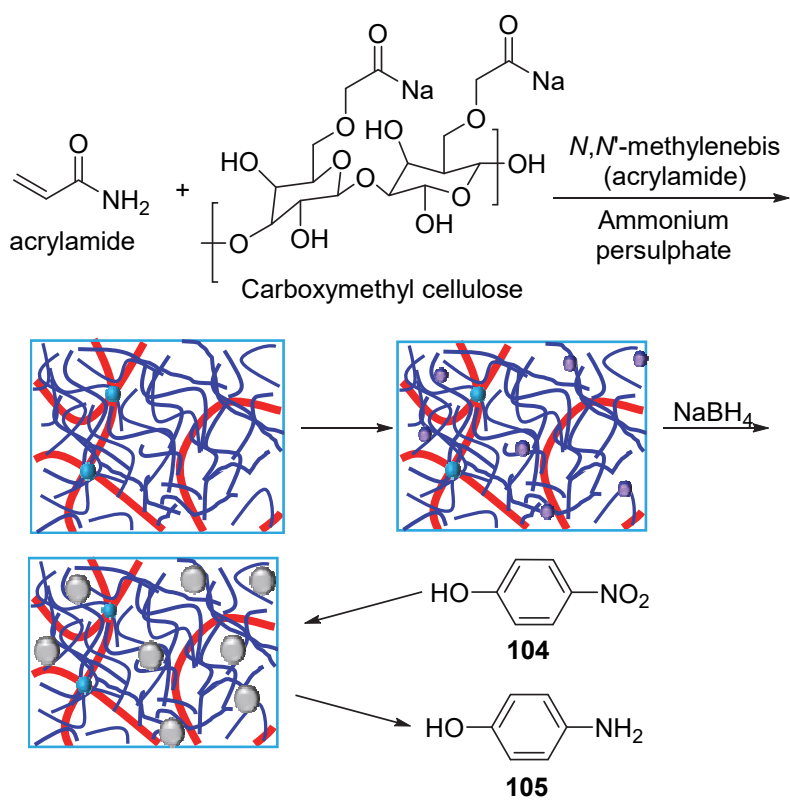

$\sim$ Poly acrylamide $\sim$ Carboxymethyl cellulose

MBA Copper ions Copper nanoparticles

图式 $31 \mathrm{Cu}$ NPs@CMC/PAM 的制备及 4-NP 的还原反应 Scheme 31 Preparation of $\mathrm{Cu}$ NPs@CMC/PAM and the reduction of 4-NP

2018 年, 李倩课题组 ${ }^{[49]}$ 从小麦秸秆中提取纤维素, 制备了 $\mathrm{Cu}$ 纳米复合材料 $\mathrm{Cu} / \mathrm{WSC}$, 用其催化还原氯霉 素(Eq. 16). 2019 年, 该小组 ${ }^{[50]}$ 又利用 $[\mathrm{Bmim}] \mathrm{Cl}$ 离子液 体制备了小麦秸秆纤维素(WSC)和羽毛蛋白(FP)衍生的 磁性水凝胶并将其用作铜纳米颗粒的载体 $(m-\mathrm{WSC} / \mathrm{FP}-$ $\mathrm{Cu}$ ), 实现了 2-硝基苯甲酸(2-NA)到 2-氨基苯甲酸 (2-ABA)的还原催化(Eq. 17).

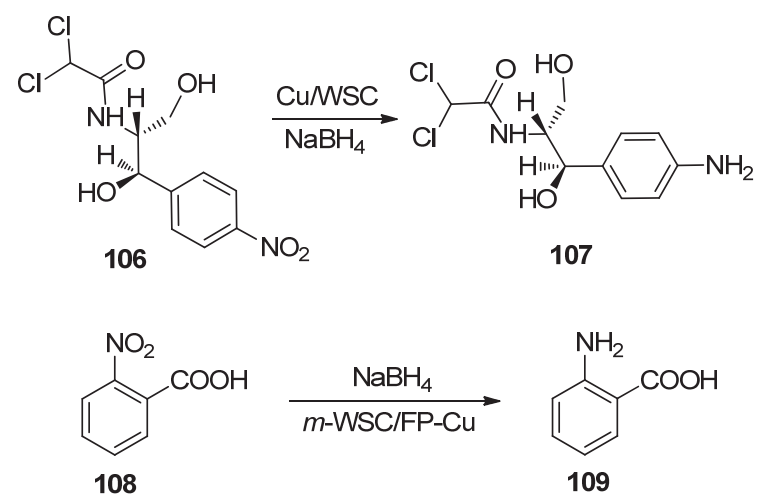

2018 年, Karami 等 ${ }^{[51]}$ 报道了将双金属 $\mathrm{Fe}-\mathrm{Cu}$ 的磁性 纳米颗粒固定在微晶纤维素上(Scheme 32), 得到的纤 维素型催化剂对 $\mathrm{NaBH}_{4}$ 还原硝基芳烃表现出极好的催 

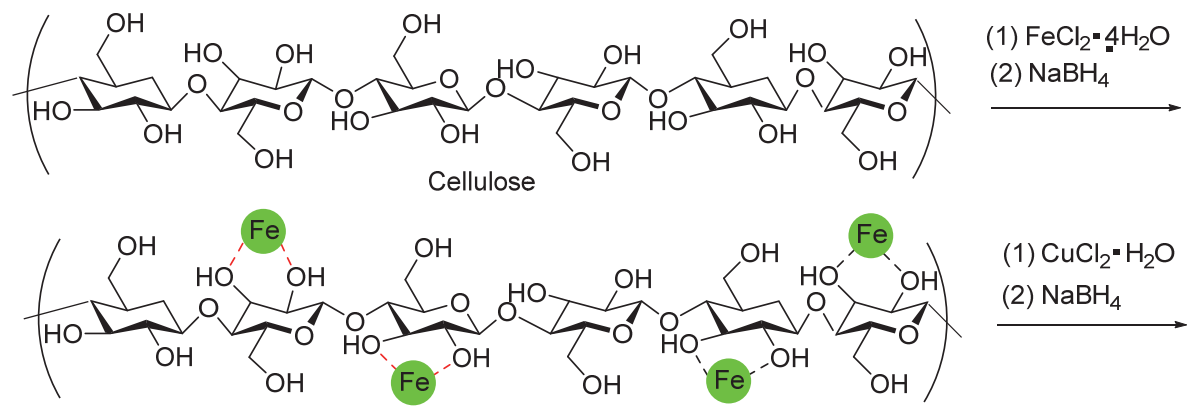

Fe@MCC

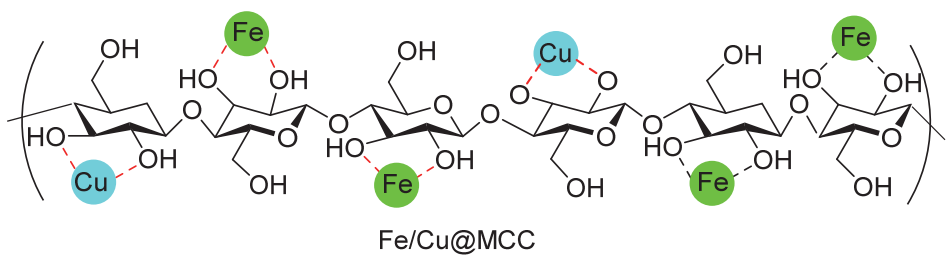

图式 $32 \mathrm{Fe} / \mathrm{Cu} @ \mathrm{MCC}$ 的制备

Scheme 32 Preparation of $\mathrm{Fe} / \mathrm{Cu} @ \mathrm{MCC}$

化活性(Eq. 18). 经研究发现在水中所有还原反应均在 5 14 min 内完成，以 89\% 95\%的收率得到芳基胺. $\mathrm{Fe}-\mathrm{Cu} @ \mathrm{MCC}$ 易于通过外部磁体从反应混合物中分离出 来, 可重复使用 8 次而其催化活性不会显著降低.

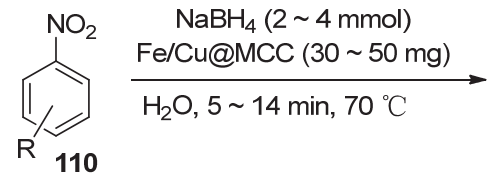

2019 年, Karami 等 ${ }^{[52]}$ 将 $\mathrm{Fe}_{3} \mathrm{O}_{4} @ \mathrm{SiO}_{2} @ \mathrm{Cell}$ 经过甲 基丙烯酸缩水甘油酯(GMA)和乙二胺(EDA)官能化后, 吸附 $\mathrm{Cu}^{2+}$ 离子制备了有机-无机杂化的磁性纤维素, 并 成功地将其用作还原 4-NP 的高效催化剂体系 (Scheme 33). 同年, 张俊华课题组 ${ }^{[33]}$ 以纳米原纤化纤维素(NFC) 作为 $\mathrm{Ru}-\mathrm{Cu}$ 纳米粒子的多功能载体, 用于 5-着基甲基糠 醛(HMF)催化转移加氢合成 2,5-二差裂甲基呋喃(BHMF). 实验证明 $\mathrm{Ru}$ 和 $\mathrm{Cu}$ 纳米颗粒能够均匀分布在 $\mathrm{NFC}$ 的表 面上, 并且 $\mathrm{NFC}$ 在 $210{ }^{\circ} \mathrm{C}$ 的温度下具有良好的热稳定 性. 整个反应体系使用异丙醇作为 $\mathrm{H}$ 供体, 在 $210{ }^{\circ} \mathrm{C}$ 下 在 $12 \mathrm{~h}$ 内获得了 $91.5 \%$ 的最高 BHMF 产率, Ru$\mathrm{Cu} @ \mathrm{NFC}$ 是一种高效且耐用的催化剂，可以连续使用 至少三次，其催化活性不会明显降低 (Scheme 34). 此 外, 周小凡课题组 ${ }^{[54]}$ 成功合成了纳米纤维素 $\mathrm{MOF}$ 衍生 的碳掺杂 $\mathrm{CuO} / \mathrm{Fe}_{3} \mathrm{O}_{4}$ 复合材料, 制备的纳米复合催化剂 由 $\mathrm{Fe}_{3} \mathrm{O}_{4} 、 \mathrm{CuO}$ 和碳组成, 并成功实现了其催化的 4-NP 高效还原. 值得一提的是, 碳的掺入避免了 $\mathrm{CuO} / \mathrm{Fe}_{3} \mathrm{O}_{4}$ 的聚集, 表现出优异的化学稳定性, $\mathrm{Fe}_{3} \mathrm{O}_{4}$ 纳米颗粒的加 入使整个催化剂具有超顺磁性，反应后易于使用外部磁 体来回收.
(1) $\mathrm{FeCl}_{3} \cdot 6 \mathrm{H}_{2} \mathrm{O}+\mathrm{FeCl}_{3} \cdot 4 \mathrm{H}_{2} \mathrm{O} \frac{\mathrm{NH}_{4} \mathrm{OH}, \mathrm{N}_{2}}{80{ }^{\circ} \mathrm{C}, 30 \mathrm{~min}} \cdot \mathrm{Fe}_{3} \mathrm{O}_{4}$

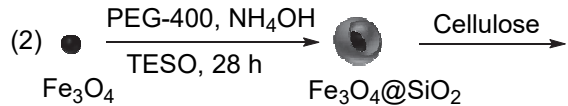

(3)<smiles></smiles>

(4)

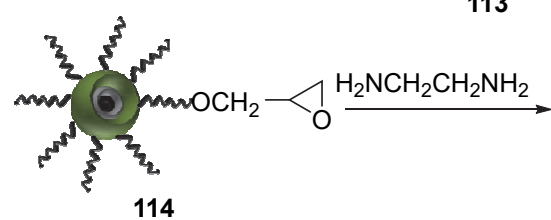

$\mathrm{Fe}_{3} \mathrm{O}_{4} @ \mathrm{SiO}_{2} @$ Cellulose@poly-GMA

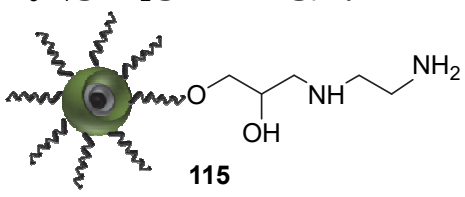

$\mathrm{Fe}_{3} \mathrm{O}_{4} @ \mathrm{SiO}_{2} @$ Cellulose@poly-GMA@EDA

图式 $33 \mathrm{Fe}_{3} \mathrm{O}_{4} @ \mathrm{SiO}_{2} @$ Cellulose@poly-GMA@EDA 纳米复 合物的制备

Scheme 33 Preparation of $\mathrm{Fe}_{3} \mathrm{O}_{4} @ \mathrm{SiO}_{2} @$ Cellulose@polyGMA@EDA nanocomposite system

2020 年, Khan 课题组 ${ }^{[55]}$ 又将铜纳米颗粒嵌入在醋 酸纤维素 $(\mathrm{CA})$ 和二氧化铈/氧化锆 $(\mathrm{Ce} / \mathrm{Zr}$ ) 薄膜上制备了 $\mathrm{Ce} / \mathrm{Zr} @ \mathrm{Cu}^{0}$. 在还原剂的存在下，该催化剂在水性介质 中表现出优异的催化效率, 可将 4-NP 还原为 4-AP, 而 且可以降解阳离子染料亚甲基蓝(MB)和罗丹明 $\mathrm{B}(\mathrm{RB})$. 但是，他们观察到反应中 $\mathrm{Cu}^{0} \mathrm{NPs}$ 存在浸出性，导致可 循环性降至 5 次. 


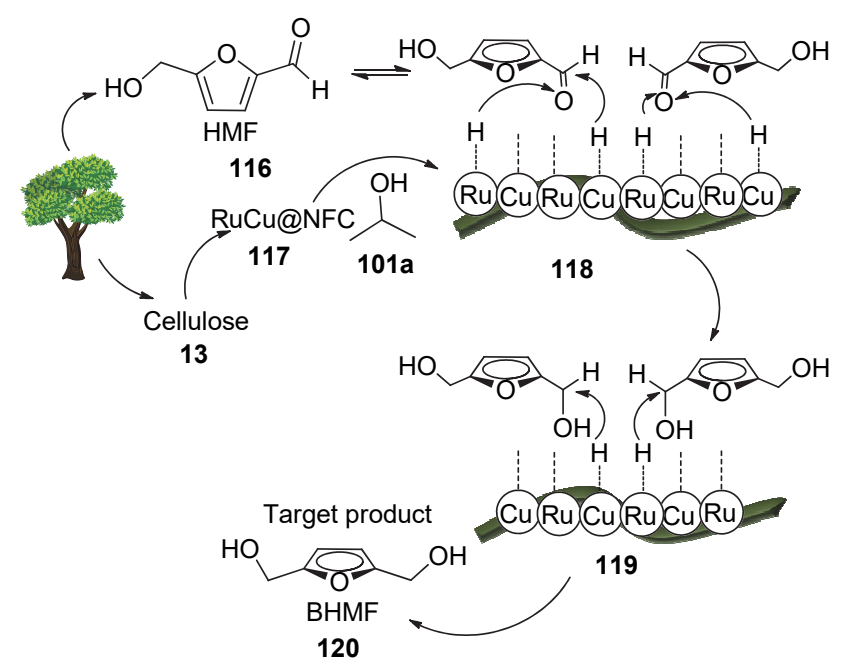

图式 $34 \mathrm{HMF}$ 催化转移加氢合成 BHMF 示意图

Scheme 34 Schematic representation for the catalytic transfer hydrogenation of HMF to BHMF

\section{5 纤维素及其衍生物负载铜实现染料的光催化 降解}

2015 年, 李洪亮课题组 ${ }^{[46]}$ 发现 CCMs 还可以用作 Fenton 催化剂, 在 $\mathrm{H}_{2} \mathrm{O}_{2}$ 条件下实现有机染料(图 3)的降 解. 其机理表现为可见光照射下, 有机物同双氧水溶液 扩散到催化剂表面的活性位点并发生吸附, 随后在纤维 素铜的催化作用下, 过氧化氢分解产生・OH 自由基, 从 而引发自由基链式反应将有机物氧化降解, 最后降解产 物从催化剂表面脱附，扩散至溶液主体中.

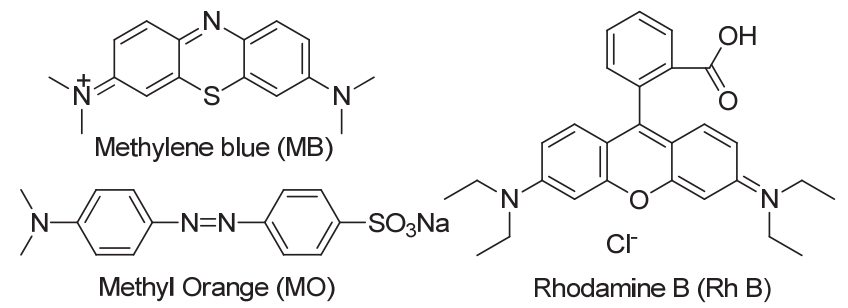

图 3 常见的有机染料

Figure 3 Common organic dyes

2017 年, 胡英等 ${ }^{[56]}$ 以木醋杆菌为菌种, 在 $30{ }^{\circ} \mathrm{C}$ 下 静态培养得到纤维素纳米纤维构建的网状薄膜, 浸泡在 硫酸铜溶液后, 经葡萄糖还原产生的氧化亚铜跟纤维素 纳米纤维紧密结合, 制备了 $\mathrm{Cu}_{2} \mathrm{O} / \mathrm{Cell}$ 催化剂, 并以其 为催化剂实现了对亚甲基蓝(MB)的降解. 其中, 整个过 程是在太阳光照射下于 $120 \mathrm{~min}$ 内完成, 降解率高达 $85 \%$, 相对于负载前提升了 $9 \%$. 随后，他们对纤维素纳 米纤维进行了表征, 观察到其直径为 $40 \sim 80 \mathrm{~nm}$, 对 $\mathrm{Cu}_{2} \mathrm{O}$ 的负载量达 $648.38 \mathrm{mg} / \mathrm{g}$. 由于纤维素纳米纤维之 间形成了三维网状结构, 纤维之间有大量孔洞, 因此可 以容纳较多 $\mathrm{Cu}_{2} \mathrm{O}$.
2019 年, Sharma 课题组 ${ }^{[57]}$ 通过水热法合成了由农 业废料提取的纤维素负载的 $\mathrm{CuInS}_{2}$ 纳米复合材料, 该 复合材料在可见光下可实现 $\mathrm{RhB}$ 染料光降解，循环可 达 5 次. 其降解效率是负载前的 $\mathrm{CuInS}_{2}$ 的 10 倍以上, 具 有极好的光催化性能. 同时, 作者也对光降解机理进行 了推理, 在 $200 \mathrm{~W}$ 光源的照射下, $\mathrm{CuInS}_{2}$ 的电子-空穴对 分离, 激发电子从价带 $(\mathrm{VB})$ 到达导带 $(\mathrm{CB})$, 在 $\mathrm{VB}$ 上形 成空穴, 光电子还原吸附在催化剂表面的 $\mathrm{O}_{2}$ 分子，从而 导致 $\mathrm{O}_{2}{ }^{-}$自由基的形成, Cell 和 CIS 之间发生电子转移. 然后, 活性空穴与 $\mathrm{H}_{2} \mathrm{O}$ 反应生成・ $\mathrm{OH}$, 该・ $\mathrm{OH}$ 自由基氧 化有机染料完成降解(Scheme 35).

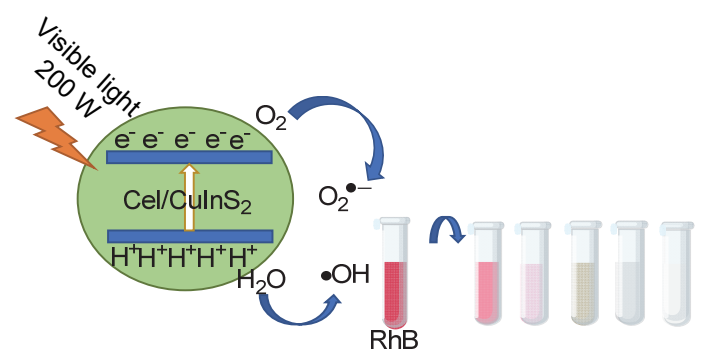

图式 35 染料降解过程的机理示意图

Scheme 35 Mechanism of dye degradation process

\section{6 纤维素及其衍生物负载铜催化电化学反应}

2020 年, Venditti 课题组 ${ }^{[58]}$ 发现磁性 $\mathrm{Fe}_{3} \mathrm{O}_{4} @ \mathrm{CNC} /$ $\mathrm{Cu}$ 纤维素复合材料对文拉法辛(Venlafaxine)具有极好的 电催化功能. 其中, $\mathrm{Cu}$ 纳米粒子的形成是在 $\mathrm{CuCl}_{2}$ 吸附 后, 采用从蜂斗菜(Petasites hybridus)叶片中提取的酚成 分还原 $\mathrm{Cu}^{2+}$ 而制备的. 之后，他们探索了用 $\mathrm{Fe}_{3} \mathrm{O}_{4} @$ $\mathrm{NC} / \mathrm{Cu}$ 修饰的丝网印刷电极对文拉法辛电催化氧化的 适用性，并且提出了相应的机理过程(Scheme 36).

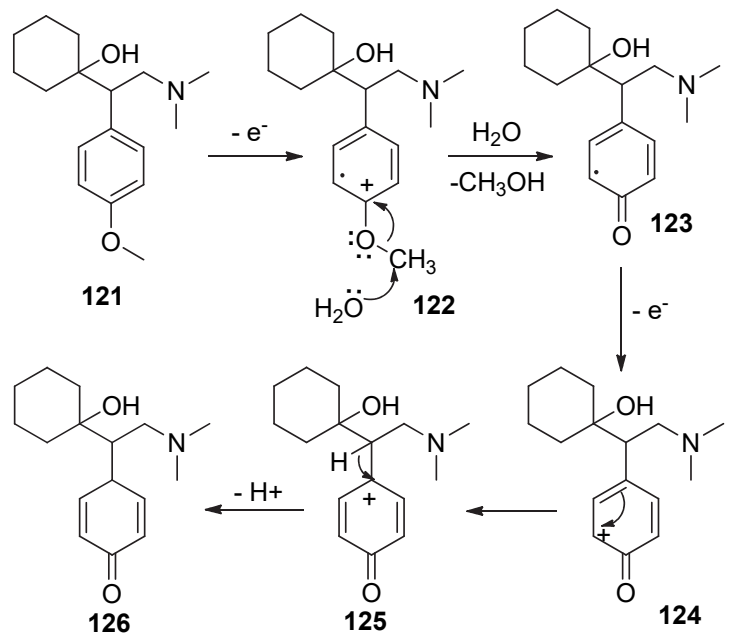

图式 $36 \mathrm{Fe}_{3} \mathrm{O}_{4} @ \mathrm{CNC} / \mathrm{Cu} / \mathrm{GSPE}$ 表面的文拉法辛可能发生的 电氧化机理

Scheme 36 Electrooxidation mechanisms for venlafaxine at the surface of $\mathrm{Fe}_{3} \mathrm{O}_{4} @ \mathrm{CNC} / \mathrm{Cu} / \mathrm{GSPE}$ 
2020 年, 乔锦丽课题组 ${ }^{[59]}$ 利用细菌纤维素(BC)通 过原位化学还原技术制备了一种高度分散的 $\mathrm{Cu}-\mathrm{CuO}$ 纳 米复合材料 $\left(\mathrm{CuO} / \mathrm{Cu}_{4: 3} @ \mathrm{BC}\right)$ 催化剂电极, 用于催化将 $\mathrm{CO}_{2}$ 高效电还原为 $\mathrm{CO}$. 实验证明, 整个反应实在 490 $\mathrm{mV}$ 的超小电势下进行, 和常规碳纸负载的 $\mathrm{CuO} / \mathrm{Cu}$ 复 合催化剂电极相比, 该催化电极具有更高的活性表面 积、较低的电荷转移电阻和出色的电荷传输性能, 从而 使 $\mathrm{CO}_{2}$ 更容易接近电解质的活性位点, 反应速率加快. 同时, 经测试其催化效率为 $53 \%$, 并且在 $40 \mathrm{~h}$ 内具有持 久活性.

\section{7 纤维素及其衍生物负载铜在其他类型反应中}

\section{的应用}

\section{1 去除保护基}

2014 年, Konwar 课题组 ${ }^{[60]}$ 在中性条件下使用纤维 素上负载的铜纳米颗粒将䏡、亚胺和嗪脱保护形成相应 的羰基. 其中, 反应是用微波辐射 $80 \sim 100{ }^{\circ} \mathrm{C}$ 下在水中 进行, 不仅可以得到产率高达 $89 \%$ 的产物, 而且反应具 有时间短、无需使用任何昂贵的配体及催化剂可以回收 利用等优点. 经研究证明该催化系统存在 $\mathrm{Cu}(0)$ 和 $\mathrm{Cu}(\mathrm{I})$ 的混合物, 并在反应初期与碳氮双键 $(\mathrm{C}=\mathrm{N})$ 上的氮配 位. 之后，他们以肟为例探究了完整的去保护机理：反 应始于 $\mathrm{Cu}(0)$ 的氧化加成并插入肜中以生成中间体 $\mathbf{1 2 6}$, 然后水对 126 亲核进攻形成中间体 127,127 由于性质不 稳定快速发生裂解，从而释放出羰基(Scheme 37).

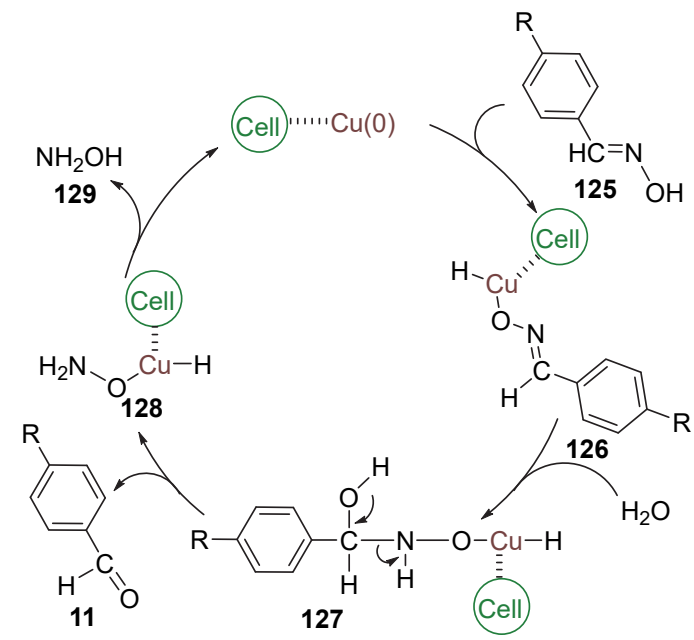

图式 $37 \mathrm{Cell}-\mathrm{Cu}(0)$ 脱肟的可能机理

Scheme 37 A plausible mechanism for the deoximation using Cell- $\mathrm{Cu}(0)$

\section{2 脱羧反应}

2015 年, Konwar 课题组 ${ }^{[61]}$ 又报道了在不使用碱或 配体的情况下，利用 Cell- $\mathrm{Cu}(0)$ 将芳基和乙烯基羧酸还 原脱羧为相应的芳烃和烯烃, 在 $\mathrm{O}_{2}$ 气氛下催化苯乙酸
氧化脱羧为芳族酫，并在无 $\mathrm{O}_{2}$ 条件下催化苯乙酸脱羧 为烷基苯(Scheme 38). 整个反应过程是在微波加热下, 乙腈或水溶剂中进行, 温和的反应条件足以耐受各种不 同的官能团，而且 $\mathrm{Cell}-\mathrm{Cu}(0)$ 在该反应中重复使用多达 四次. 同时，作者也提出了相应的脱羧机理：首先羧酸 衍生物在 $\mathrm{Cu}(\mathrm{I})$ 下催化形成铜酸盐 $\mathbf{1 3 1}$ ，进一步脱羧产生 两种活性中间体 132 或 132a; 其中相对不稳定的铜酸芳 基酯 132 经历非常快的质子提取得到相应的芳烃; 但是, 由苯乙酸脱羧获得的中间体 132a 会被空气中的氧气氧 化生成过氧铜酸盐 134, 最后还原消除得到酫(Scheme 39).

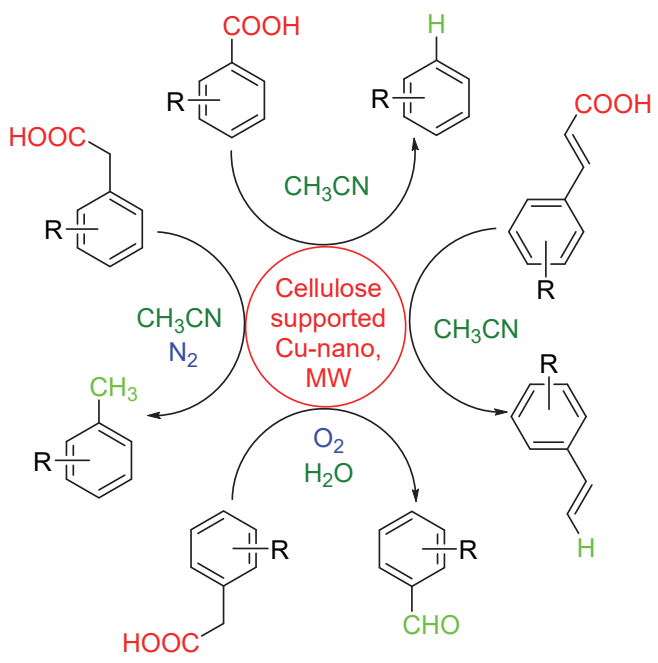

图式 $38 \mathrm{Cell}-\mathrm{Cu}(0)$ 催化的脱羧反应

Scheme 38 Decarboxylation for the catalysis of cell- $\mathrm{Cu}(0)$

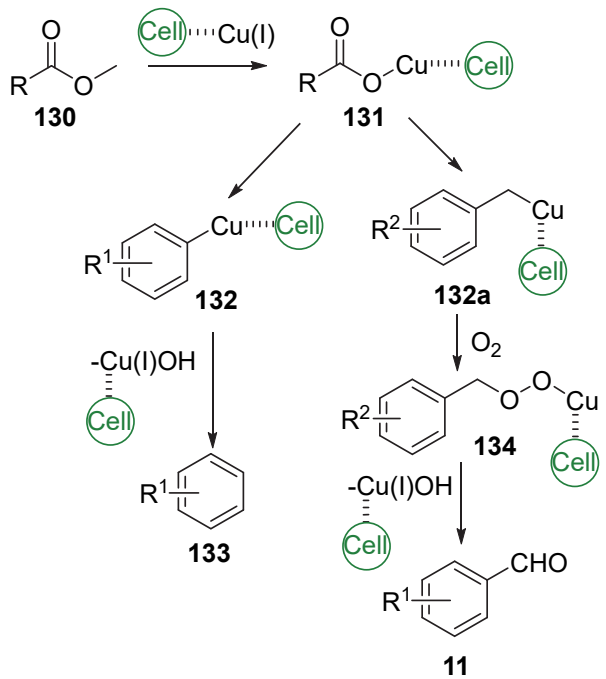

图式 39 脱羧反应机理

Scheme 39 Proposed mechanism for the decarboxylation reactions

同年，该小组 ${ }^{[62]}$ 利用 $\mathrm{Cell}-\mathrm{Cu}(0)$ 又对苯甲酸和肉桂 酸进行脱羧硝化，以极好的收率得到硝基苯和 $(E)$-硝基 
烯烃(Eqs. 19，20). 反应过程中肉桂酸衍生物在与铜纳 米粒子反应先形成 $\mathrm{Cu}(\mathrm{II})$ 盐 140 , 然后在氧气氛围中 $\mathrm{Bi}\left(\mathrm{NO}_{3}\right)_{3} \cdot 5 \mathrm{H}_{2} \mathrm{O}$ 通过均相裂解形成 $\mathrm{NO}_{2}$ 自由基, 140 在与 其反应生成苄基自由基 141, 最终, 茮基自由基 141 进 行脱羧反应生成相应的 $(E)$-硝基烯烃(Scheme 40). 反应 后, 由于 $\mathrm{Cu}$ 纳米颗粒被氧化成 $\mathrm{Cu}^{2+}$, 因此该催化剂无 法回收再利用. 但可以通过过滤将纤维素收集起来, 重 新负载合成铜纳米颗粒再使用.

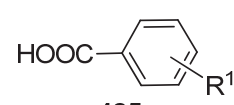

135
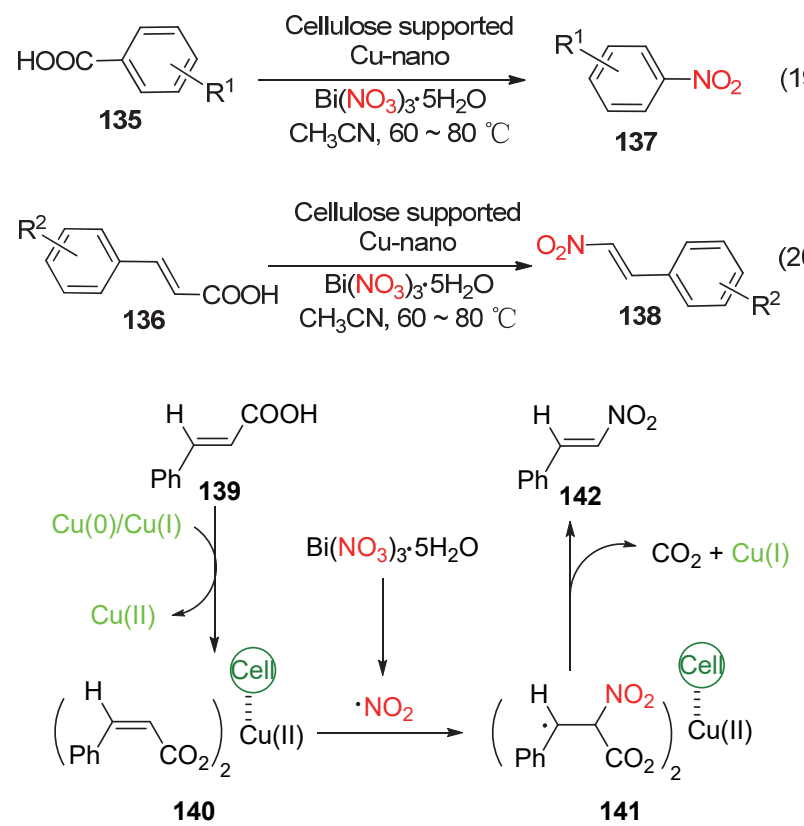

图式 40 脱羧硝化可能的机理

Scheme 40 Proposed reaction pathway of decarboxylative nitration reaction

\section{3 分解反应}

2020 年, DeCoster 课题组 ${ }^{[63]}$ 开发了一种新型的胱氨 酸铜生物复合材料, 通过 EDC/NHS 将聚烯丙胺 $(\mathrm{PAH})$ 与 TEMPO 氧化的纤维素共价接合, 然后再负载 CuHARS 而成, 整个过程通过溶剂浇铸和冻干将所得材 料加工成膜或大孔泡沫. 由于该膜具有良好的机械性 能, 并且在水中具有抵抗力, 能形成大孔开放网络结构 其平均直径约为 $130 \mu \mathrm{m}$, 从而对低分子量 $S$-亚硝基硫 (RSNO) 释放出一氧化氮(NO)的分解反应中拥有极佳的 催化性能. 值得一提的是, 该小组通过实验监测到该材 料还对大肠杆菌和表皮葡萄球菌显示出良好的抗菌活 性. 近年来, 纤维素铜络合物的不断发展表现出的抑菌

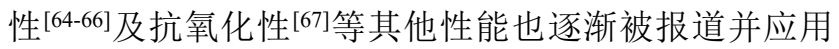
到不同领域里.

\section{8 总结与展望}

多年以来, 相对于贵重金属的使用, 廉价金属铜作
为催化剂不断引起人们极大的兴趣, 顺应 “绿色化学”, 且在许多重要化学品的合成中铜催化剂是不可或缺的, 但铜催化剂的失活也一直是科研工作者的顾虑, 因此将 铜催化剂固载于生物可再生材料上, 不仅能解决回收再 利用的问题，还能使整个反应体系变得更温和快捷. 自 2006 年 Reddy 课题组报道了 Cell- $\mathrm{Cu}(0)$ 可以催化构建 $\mathrm{C}-\mathrm{N}$ 键以来, 不同类型的纤维素负载铜催化剂及应用 被相继报道. 本文对近年来纤维素及其衍生物负载铜催 化剂在催化有机反应方面的进展进行了归纳，文中主要 涉及 $\mathrm{C}-\mathrm{X}$ 键的构建、环加成、氧化、还原、光催化降 解、电催化等反应类型. 虽然纤维素铜催化剂在这些反 应中都表现出了极好的催化效果, 但也存在诸如铜负载 率低、纤维素本身或纤维素负载金属催化剂分解以及回 收重复使用活性降低等问题. 目前, 在科研工作者不断 的探究中, 开拓了不同形态纤维素载体, 或者对纤维素 本身进行化学修饰, 得到的一系列多功能化纤维素衍生 物再去负载铜或铜离子, 不仅拥有较好的催化活性, 而 且是延长催化剂使用寿命的高效途径.

此外，生物聚合物负载技术和现代表征技术为催化 剂的催化性能提供了基础和证明. 如今尽管解决了催化 剂分离和回收有关的难题, 但铜络合物的浸出仍然需要 改良. 相信随着纤维素及其衍生物负载应用的蓬勃发展 及广大科研工作者的不断努力, 更完善的催化体系将被 开发, 更多的生物质材料将被应用到有机催化领域中 来.

\section{References}

[1] Shaghaleh, H.; Xu, X.; Wang, S. RSC Adv. 2018, $8,825$.

[2] Qiu, X.; Hu, S. Materials 2013, 6, 738.

[3] McNamara, J. T.; Morgan, J. L. W.; Zimmer, J. Annu. Rev. Biochem. 2015, 84, 895.

[4] Brett, C. T. Int. Rev. Cytol. 2000, 199, 161.

[5] Wu, X.; Lu, C.; Zhang, W.; Yuan, G.; Xiong, R.; Zhang, X. J. Mater. Chem. 2013, 30, 8645.

[6] Wu, X.; Lu, C.; Zhang, W.; Guan, G.; Xiong, R.; Zhang, X. Environ. Sci.: Nano 2014, 1, 71.

[7] Zhou, Z.; Lu, C.; Wu, X.; Zhang, X. RSC Adv. 2013, 48, 26066.

[8] Klemm, D.; Heublein, B.; Fink, H. P.; Bohn, A. Angew. Chem., Int. Ed. 2005, 44, 3358.

[9] Varshney, K.; Naithani, S. In Cellulose Fibers: Bio- and Nano-Polymer Composites, Green Chemistry and Technology, Eds.: Kalia, S.; Kaith, B. S.; Kaur. I., Springer Science \& Business Media, New York, 2011, pp. 43 60

[10] Saliba, R.; Gauthier, H.; Gauthier, R.; Ramel, M. P. J. Appl. Polym. Sci. 2000, 75, 1624.

[11] Bang, H.; Ma, K.; Devarayan, K.; Kang, C.; Kim, B.; Gopiraman, M.; Kim, I. J. Mater. Sci. Technol. 2016, 32, 605.

[12] Eivazihollagha, A.; Bäckströmb, J.; Dahlströma, C.; Carlssonc, F.; Ibrahema, I.; Lindmana, B.; Edlunda, H.; Norgren, M. Mater. Lett. 2017, 187, 170.

[13] Jilal, I.; Barkany, S. E.; Bahari, Z.; Sundman, O.; Loutou, M.; Amhamdi, H. Cellulose 2018, 25, 4375.

[14] Yingkong, P.; Tanskul, S. J. Polym. Environ. 2019, 27, 1948.

[15] Li, Z.; Hori, N.; Takemura, A. Cellulose 2019, 6, 2839.

[16] Reddy, K. R.; Kumar, N. S.; Sreedhar, B.; Kantam, M. L. J. Mol. 
Catal. A: Chem. 2006, 252, 136.

[17] Reddy, K. R.; Kumar, N. S. Synlett 2006, 2246.

[18] Zhai, X.; Han, S.; Wei, P. Chem. Reagents 2010, 32, 397 (in Chinese) (篗晓璐，韩世清，韦萍，化学试剂， 2010, 32, 397.)

[19] Sarkar, S. M.; Sultana, T.; Biswas, T. K.; Ranman, M. L.; Yusoff, M. M. New J. Chem. 2016, 40, 497.

[20] Liu, X.; Lin, B.; Zhang, Z.; Lei, H.; Li, Y. RSC Adv. 2016, 6, 94399

[21] Jiang, Y.; Guo, N.; Li, X.; Sun, Y.; Zhang, W. Z. Naturforscher 2017, 72, 549 .

[22] Martins, G. B. C.; Santos, M. R.; Rodrigues, M. V. R.; Sucupira, R. R.; Meneghetti, L.; Monteirob, A. L.; Suarez, P. A. Z. J. Braz. Chem. Soc. 2017, 28, 2064.

[23] Shojaei, S.; Ghasemi, Z.; Shahrisa, A. Appl. Organomet. Chem 2017, 31, e3788

[24] Shojaei, S.; Ghasemi, Z.; Shahrisa, A. Tetrahedron Lett. 2017, 58, 3957.

[25] Maleki, A.; Eskandarpour, V.; Rahimi, J.; Hamidi, N. Carbohyd. Polym. 2019, 208, 251.

[26] Goswami, M.; Das, A. M. Carbohydr. Polym. 2018, 195, 189.

[27] Jeremic, S.; Djokic, L.; Runic, J. N. Int. J. Biol. Macromol. 2019, 129,351

[28] Sharpless, K. B. Angew. Chem. 2001, 113, 2056.

[29] Koga, H.; Azetsu, A.; Tokunaga, E.; Saito, T.; Isogaia, A.; Kitaoka, T. J. Mater. Chem. 2012, 22, 5538.

[30] Chavan, P. V.; Pandit, K. S.; Desai, U. V.; Kulkarnia, M. A.; Wadgaonkar, P. P. RSC Adv. 2014, 4, 42137.

[31] Pourjavadi, A.; Habibi, Z. RSC Adv. 2015, 5, 99498.

[32] Yu, W.; Jiang, L.; Shen, C.; Xu, W.; Zhang, P. Catal. Commun. 2016, 79, 11.

[33] Barrull, J. R.; Halluin, M.; Grognec, E. L.; F. X.; Felpin, E. L. Angew. Chem., Int. Ed. 2016, 55, 1.

[34] (a) Mandal, B. H.; Rahmanc, M. L.; Yusoffa, M. M.; Chonga, K. F.; Sarkar, S. M. Carbohydr. Polym. 2017, 156, 175.

(b) Mandal, B. H.; Rahman, M. L.; Rahim, M. H. A.; Sarkar, S. M. ChemistrySelect 2016, 1, 2750.

[35] (a) Hajar, S.; Islam, M. S.; Sarkar, S. M. BioResources 2017, 12, 882 .

(b) Sarkar, S. M.; Rahman, M. L. J. Cleaner Prod. 2017, 141, 683.

(c) Rahman, M. L.; Sarkar, S. M. J. Nanosci. Nanotechnol. 2017, 17,550 .

[36] Benhamou K.; Kaddami, H.; Julve, M.; Stiriba, S. E. Biomacromolecules 2018, 7, 200

[37] Sá, D S.; Bustamante, R. A.; Rocha, C. E. R.; Silva, V. D.; Pandoli, O. G. ACS Sustainable Chem. Eng. 2019, 7, 3267.

[38] Hamzavi, S. F.; Gerivani, S.; Saeedi, S.; Naghdipari, K.; Shahverdizadeh, G. Mol. Diversity 2019, 24, 201

[39] Baruah, D.; Saikia, U. P.; Pahari, P.; Konwar, D. Tetrahedron Lett. 2015, 56, 2543

[40] Chauha, P.; Yan, N. RSC Adv. 2015, 5, 37517.
[41] Shaabani, A.; Hezarkhani, Z. Cellulose 2015, 22, 3027.

[42] Nekouei, F.; Nekouei, S.; Kargarzadeh, H. Chem. Eng. J. 2018 , $335,567$.

[43] Dutta, A.; Chetia, M.; Ali, A. A.; Bordoloi, A.; Gehlot, P. S.; Kumar, A.; Sarma, D. Catal. Lett. 2019, 149, 141

[44] Shim, S. W.; Noh, W. T.; Kwon, J.; Cho, J. Y.; Kim, K. S.; Kang, D. H. Bull. Korean Chem. Soc. 2002, 23, 563.

[45] Zhou, Z.; Lu, C.; Wu, X.; Zhang X. RSC Adv. 2013, 3, 26066.

[46] Cheng, X.; Fu, A.; Li, H.; Wang, Y.; Guo, P.; Liu, J.; Zhang, J.; Zhao, X. S. ACS Sustainable Chem. Eng. 2015, 3, 2414.

[47] Khan, F. U.; Asimullah, Khan, S. B.; Kamal, T.; Asiri, A. M.; Khan, I. U.; Akhtar, K. Int. J. Biol. Macromol. 2017, 102, 868.

[48] Godiya, C. B.; Cheng, X.; Li, D.; Chen, Z.; Lu, X. J. Hazard. Mater. 2019, 364, 28.

[49] Ding, J.; Li, Q.; Xu, X.; Zhang, X.; Su, Y.; Yue, Q.; Gao, B. Carbohydr. Polym. 2018, 190, 12.

[50] Su, R.; Wang, F.; Ding, J.; Li, Q.; Zhou, W.; Liu, Y.; Gao, B.; Yue, Q. Carbohydr. Polym. 2019, 220, 202.

[51] Karami, S.; Zeynizadeh, B.; Shokri, Z. Cellulose 2018, 25, 3295.

[52] Karami, S.; Zeynizadeh, B. Carbohydr. Polym. 2019, 211, 298.

[53] Zhang, J.; Xie, W.; Liang, Q.; Peng, L.; He, L. ChemistrySelect 2019, 4, 2846

[54] Lu, H.; Zhang, L.; Ma, J.; Alam, N.; Zhou, X.; Ni, Y. Nanomaterials 2019, 9, 277.

[55] Khan, S. A.; Khan, N.; Irum, U.; Farooq, A.; Asiri, A. M.; Bakhsh, E. M.; Khan, S. B. Int. J. Biol. Macromol. 2020, 153, 806.

[56] Hu, Y.; Li, G.; Y, Zhi.; Yao, Y.; Li, Z. China Synth. Fiber Ind. 2017, 40, 24 (in Chinese).

(胡英, 李国元, 颜志勇, 姚勇波, 李喆, 合成纤维工业, 2017, 40, 24.)

[57] Tavker, N.; Gaur, U. K.; Sharma, M. ACS Omega 2019, 4, 11777.

[58] Khalilzadeh, M. A.; Tajik, S.; Beitollahi, H.; Venditti, R. A. Ind. Eng. Chem. Res. 2020, 59, 4219

[59] Zhou, Y.; Guo, X.; Li, X.; Fu, J.; Liu, J.; Hong, F.; Qiao, J. J. CO Util. 2020, 37, 188.

[60] Baruah, D.; Saikia U. P.; Pahari, P.; Duttab, D. K.; Konwar, D. RSC Adv. 2014, 4, 59338 .

[61] Baruah, D.; Konwar, D. Catal. Commun. 2015, 69, 68.

[62] Baruah, D.; Pahari, P.; Konwar, D. Tetrahedron Lett. 2015, 56, 2543.

[63] Darder, M.; Karan, A.; Real, G.; DeCoster, M. A. Mater. Sci. Eng., C 2020, 108, 110369.

[64] Sadanand, V.; Rajini, N.; Rajulu, A. V.; Satyanarayana, B. Carbohydr. Polym. 2016, 150, 32

[65] El-Mossalamy, E. H.; Khalil, A. A.; Mohmoud, H. A. J. Basic Environ. Sci. 2018, 5, 333.

[66] Xu, Y.; Shi, Y.; Lei, F.; Dai, L. Carbohydr. Polym. 2020, 230, 115671 .

[67] Ma, B.; Sun, B.; Huang, Y.; Chen, C.; Sun, D. Colloids Surf., A 2020, 590, 124462 . 